\title{
Review
}

\section{Functional zonation of the rat adrenal cortex: the development and maintenance}

\author{
By Fumiko Mitani*1,*2,† \\ (Communicated by Masanori OTsukA, M.J.A.)
}

\begin{abstract}
The adrenal cortex of mammals consists of three concentric zones, i.e., the zona glomerulosa $(\mathrm{zG})$, the zona fasciculata $(\mathrm{zF})$, and the zona reticularis $(\mathrm{zR})$, which secrete mineralocorticoids, glucocorticoids, and adrenal androgens, respectively. In 1994, we identified immunohistochemically a new zone between $\mathrm{zG}$ and $\mathrm{zF}$ of the rat adrenal gland. The zone appeared to be devoid of any significant endocrine functions specific to adrenocortical zones, therefore, we designated the zone as "undifferentiated cell zone (zU)". Further, BrdU (5-bromo-2'-deoxyuridine)incorporating cells (cells in S-phase) were concentrated at the outer region and the inner region of $\mathrm{zU}$, and these cells proliferated and migrated bidirectionally: toward zG centrifugally and toward zF centripetally. We proposed that cells in and around $\mathrm{z} U$ are stem/progenitor cells of the rat adrenal cortex, maintaining functional zonation of the adrenal cortex. The view is consistent with observations reported recently that Sonic hedgehog (Shh), an important factor in embryonic development and adult stem cell maintenance, exists in zU of the rat adrenal gland and the Shhcontaining cells seem to migrate bidirectionally.
\end{abstract}

Keywords: adrenal cortex, steroidogenesis, aldosterone synthase cytochrome P450 (CYP11B2), steroid 11ß-hydroxylase cytochrome P450 (CYP11B1), stem/progenitor cells of the adrenal cortex, functional zonation of the adrenal cortex

\section{Introduction}

The adrenal cortex is composed of a wellorganized structure and functions in corticosteroid

*1 Former Senior Lecturer, School of Medicine, Keio University, Tokyo, Japan.

*2 Former Senior Lecturer, Faculty of Science and Engineering, Waseda University, Tokyo, Japan.

$\dagger \quad$ Correspondence should be addressed: F. Mitani, 1-4-7-101, Nishikata, Bunkyo-ku, Tokyo 113-0024, Japan (e-mail: fmitani8@ gmail.com).

Abbreviations: ACTH: Adrenocorticotropic hormone P450: cytochrome P450; SF-1/Ad4BP: steroidogenic factor-1/ Ad4-binding protein; BrdU: 5-bromo-2'-deoxyuridine; CYP11A1: cholesterol side-chain cleavage enzyme cytochrome P450 (formerly termed P450scc); CYP11B1: steroid $11 \beta$-hydroxylase cytochrome P450 (P45011及); CYP11B2: aldosterone synthase cytochrome P450 (P450aldo); CYP21: steroid 21-hydroxylase cytochrome P450 $\left(\mathrm{P} 450_{\mathrm{C} 21}\right)$; CYP17: steroid $17 \alpha$-hydroxylase/lyase cytochrome P450 (P45017 $)$; 3 $\beta$-HSD: 3 $\beta$-hydroxysteroid dehydrogenase; PCNA: proliferating cell nuclear antigen; RAS: renin-angiotensin system; zG: zona glomerulosa; zF: zona fasciculata; zR: zona reticularis; zFR: zonae fasciculata-reticularis; $z \mathrm{U}$ : undifferentiated cell zone; SDS-PAGE: sodium dodecyl sulfate-polyacrylamide gel electrophoresis; SV40: simian virus 40. production. My colleagues and I have been working since the late 1960s to elucidate properties of steroid hydroxylases and the development and maintenance of functional zonation of the adrenal cortex. This review examines our work together with a brief historical outline of the adrenal gland and steroid hormone metabolism, including 1) purification and characterization of steroid hydroxylases, 2) immunohistochemical localization of the zone-specific steroid hydroxylases, 3) discovery of a new zone, the undifferentiated cell zone $(\mathrm{zU}), 4)$ the possible functional significance of $\mathrm{zU}$ as a stem/progenitor cell zone, and 5) the development and maintenance of functional zonation in the rat adrenal cortex in relation to $\mathrm{zU}$.

\section{The adrenal gland}

The adrenal glands are a pair of triangular or round bodies located adjacent to the superior pole of each kidney. They show a combined weight of about $10-15 \mathrm{~g}$ in humans, and $40-60 \mathrm{mg}$ in rats. The gland may have been described in 1563 by Barthlomeo 
Eustachi, an Italian anatomist, as the "glandulae renis incumbents" with no distinct description of its function. ${ }^{1)}$ The first report on a physiological role of the adrenal gland was presented almost 3 centuries later (1855) by Thomas Addison, ${ }^{2)}$ an English doctor. In his paper entitled "On the constitutional and local effects of disease of the suprarenal capsules", he stated that "a remarkable form of idiopathic anemia" was associated with disease of the suprarenal capsules. Although the idiopathic pernicious anemia was very similar to other fatal forms of anemic disorder, he noticed that some of his patients showed "bronzed skin" or "melasma". The disease is now recognized as Addison's disease, ${ }^{3)}$ which is due entirely to insufficiency in function of the adrenal cortex. The main features of Addison's disease are anemia, fatigue, feebleness of heart activity, irritability of the digestive organs, and a peculiar dark pigmentation of the skin, which are all suggestive for the function of the adrenal cortex.

It is now known that the adrenal gland consists of two ontogenetically, structurally and functionally distinct endocrine tissues, the cortex and the medulla. ${ }^{4)}$ The cortex is mesodermal in origin and derived from proliferation of the coelomic epithelium. It produces various steroids with specific functions as will be described later. The medulla, on the other hand, is ectodermal in origin and neural crestderived. It secretes catecholamines, i.e., adrenaline and noradrenaline, that facilitate the acute mammalian stress or "fight-or-flight" response. The cortex is further subdivided into concentric zones, the zona glomerulosa $(\mathrm{zG})$, the zona fasciculata $(\mathrm{zF})$ and the zona reticularis $(\mathrm{zR})$, which were originally named by Arnold in 1866 from the morphological appearance or shape of the cells in each zone (glomus, ball; fascis, bundle; and rete, net) rather than from function. ${ }^{5)}$ Later it was established that each zone has specific endocrine functions.

\section{Early history of research on adrenocortical hormones: extracts from the adrenal cortex and the physiological effect}

In 1930, Swingle and Pfiffner prepared an aqueous lipid extract from bovine suprarenal cortex. ${ }^{6)}$ They administered the extract to bilaterally adrenalectomized animals and restored the animals to a normal condition. ${ }^{7), 8)}$ Subsequently, the apparent efficacy of such an extract on patients with Addison's disease was confirmed. ${ }^{9), 10)}$ Chemical investigations of adrenal steroids and their syntheses began around 1935 through the work of Wintersteiner and
Pfiffner, ${ }^{11)}$ Reichstein's group ${ }^{12)}$ and Kendall's group. ${ }^{13)}$ Kendall isolated 6 active adrenocortical hormones from the adrenal gland and named them in the order in which they were isolated, i.e., Compound A through F (Compound A is 11-dehydrocorticosterone, Compound B is corticosterone or Reichstein's substance H, Compound C is $5 \alpha$ pregnane-3 $\alpha, 11 \beta, 17 \alpha, 21$-tetrol-20-one or Reichstein's substance $\mathrm{C}$, Compound D is $5 \alpha$-pregnane$3 \beta, 11 \beta, 17 \alpha, 20 \beta, 21$-pentol or Reichstein's substance A, Compound $\mathrm{E}$ is cortisone or Reichstein's substance F, and Compound F is cortisol or Reichstein's substance M). Their studies enabled semisynthetic production of adrenocortical hormones with a good yield from the more easily obtainable materials, such as bile acids. The first clinical investigation on the effect of the synthetic compound was performed in 1948 at the Mayo Clinic. Hench's group in collaboration with Kendall injected Compound E (cortisone) intramuscularly into a patient with severe rheumatoid arthritis. Improvement in the clinical features of the patient began to occur within a few days. ${ }^{14), 15)}$ When Compound E administration was discontinued, the symptoms relapsed promptly, and the readministration alleviated the symptoms again, suggesting that Compound $\mathrm{E}$ has some antiinflammatory and energy metabolism function. In 1950, Drs. Kendall, Hench and Reichstein shared the Nobel Prize in Physiology or Medicine "for their discoveries relating to the hormones of the adrenal cortex, their structure and biological effects".

Further work revealed the features of most of the steroids in adrenal extracts, but an "amorphous fraction" of the adrenal extracts, designated at that time as "electrocortin", was not identified until 1954. Tait's group isolated the electrocortin from the adrenal extracts, crystallized the compound, and established the chemical structure. ${ }^{16)}$ The term of "electrocortin" was then supplanted by the term "aldosterone" in reference to the structure of the crystalline compound. The biological activity of the crystalline aldosterone in electrolyte balance was demonstrated $^{17), 18)}$ based on depression of the urinary $\mathrm{Na}^{24} / \mathrm{K}^{42}$ ratio in adrenalectomized rat. ${ }^{19)}$

\section{Early studies on steroidogenic enzymes in the adrenal cortex}

3-1) Steroid hydroxylations and the participation of hemoprotein cytochrome P450. A breakthrough in steroid metabolism of the adrenal cortex occurred through the study of steroid 21hydroxylation. In 1952, Hayano and Dorfman 
showed that bovine adrenal homogenates catalyzed the formation of 21-hydroxylated derivatives from progesterone, 17-hydroxyprogesterone and 21-desoxycortisone, demonstrating the presence of an enzyme system capable of catalyzing C21-hydroxylation in the adrenal homogenate. ${ }^{20)}$ They also demonstrated C11-hydroxylation of deoxycorticosterone in bovine adrenal mitochondrial fraction. In their studies, molecular oxygen, $\mathrm{O}_{2}{ }^{18}$, but not water, $\mathrm{H}_{2} \mathrm{O}^{18}$, was found to be directly utilized in the $11 \beta$-hydroxylation system. ${ }^{21)}$ Later Ryan and Engel defined steroid 21-hydroxylation as a reaction involving TPNH (now termed NADPH) and atmospheric oxygen in addition to the microsomal fraction of the adrenal cortex. ${ }^{22)}$ The stoichiometry of C21-hydroxylation of 17-hydroxyprogesterone by bovine adrenocortical microsomes was established by Cooper et al. in 1963, showing that 1 mole of oxygen and 1 mole of NADPH were consumed per mole of 17-hydroxyprogesterone hydroxylated. ${ }^{23)}$

$$
\begin{aligned}
& \text { 17-hydroxycorticoid }+\mathrm{NADPH}+\mathrm{H}^{+}+\mathrm{O}_{2} \\
& \quad \rightarrow 17,21 \text {-dihydroxycorticoid }+\mathrm{NADP}^{+}+\mathrm{H}_{2} \mathrm{O}
\end{aligned}
$$

Thus, mechanisms of steroid C21- and $11 \beta$-hydroxylations were found to be similar to that of mixed function oxidase, as reported in 1955 by Mason et al. ${ }^{24)}$ or monooxygenase, as designated by Hayaishi et al. ${ }^{25)}$ In the reaction, 1 atom of molecular oxygen is transferred to the substrate and the other one is reduced to water by 1 mole of NADPH, and molecular oxygen is activated for the hydroxylation reaction.

In 1962, Sato and Omura examined the carbon monoxide-combined pigment of liver microsomes which was originally reported by Klingenberg. ${ }^{26)}$ The CO-complex showed an absorbance maximum at $450 \mathrm{~nm}$ in the presence of a reducing agent. They found the pigment to be a hemoprotein and named it cytochrome P450 (P450), i.e., the pigment (P) with a spectral absorbance maximum at $450 \mathrm{~nm}$ in the presence of carbon monoxide and a reducing agent. $^{27), 28)}$ Subsequently in 1963, the photochemical action spectrum of the light reversal of carbon monoxide inhibition of steroid 21-hydroxylation was obtained by Estabrook et al. using bovine adrenal cortex microsomes. ${ }^{29)-31)}$ A broad peak at around $450 \mathrm{~nm}$ in the photochemical action spectrum similar to the optical absorption spectrum of P450 confirmed the involvement of P450 in the adrenal hydroxylation reaction. ${ }^{29)}$ Carbon monoxide inhibition of the cholesterol side-chain cleavage reaction ${ }^{32,33)}$ and of the steroid 18-hydroxylation, another hydroxylation system in the adrenal mitochondria, was reported by Boyd's group in 1966 ${ }^{34)}$ and by Estabrook's group in $1967,{ }^{35)}$ respectively. Thus, these findings confirmed definitely that steroid hydroxylations in the adrenal cortex are catalyzed by the hemoprotein cytochrome P450 (reviewed in refs. 31 and 36).

3-2) Solubilization and partial purification of steroid hydroxylases from the adrenocortical membrane. By around 1970, adrenocortical microsomal P450 was shown to be involved in steroid 21-hydroxylation, and the mitochondrial P450 was shown to be involved in at least three reactions, the conversion of cholesterol to pregnenolone (cholesterol side chain cleavage reaction), steroid $11 \beta$-hydroxylation, and steroid 18-hydroxylation (reviewed in ref. 37). Whether a single species of $\mathrm{P} 450$ is responsible for all these reactions or each reaction is catalyzed by specific species of P450 remained as an interesting problem to be solved. One approach to this question was the separation and extensive purification of various $\mathrm{P} 450$ s having specific catalytic activity.

Many groups tried to extract and purify the enzymes from the adrenocortical membranes using various reagents. ${ }^{38-40)}$ One of the main difficulties was the low stability of P450 in its solubilization. The treatment of the cytochrome with monohydric alcohols, detergents, proteases, phospholipases and lower and higher $\mathrm{pH}$ values frequently caused the conversion of $\mathrm{P} 450$ to $\mathrm{P} 420$, an inactive form of cytochrome P450. ${ }^{41)}$ However, in 1967, Kinoshita in our group found that an ionic detergent, Na-cholate, was a good reagent to solubilize P450 from the mitochondrial membrane with a great amount of cytochromes $\mathrm{a}, \mathrm{b}$, and $\mathrm{c}_{1}$ remaining in the undissolved residue. ${ }^{42)}$ In 1969, Mitani and Horie improved his method for a more reproducible and well-dispersed P450 preparation with higher yield, and then partially purified P450. ${ }^{43)}$ The Na-cholate to mitochondrial protein ratio was important for this purpose (Fig. 1). Later our solubilization method with Na-cholate became a fundamental procedure for further purification of P450. ${ }^{44)-46)}$ We then examined the spectral, ${ }^{43)}$ magnetic, ${ }^{47)}$ and catalytic properties ${ }^{48)-50)}$ of the solubilized and partially purified P450 preparations as described next.

3-3) Physicochemical and catalytic properties of partially purified steroid hydroxylating enzyme, cytochrome P450. Figure 2 shows the absolute absorption spectra of our partially purified P450 from bovine adrenocortical mitochondria under various conditions. ${ }^{43)}$ The oxidized preparation had 
peaks at $394,417,535,569$, and $645 \mathrm{~nm}$, suggesting that both low and high spin species of the hemoprotein $^{51)}$ existed in the preparation. The peaks corre-

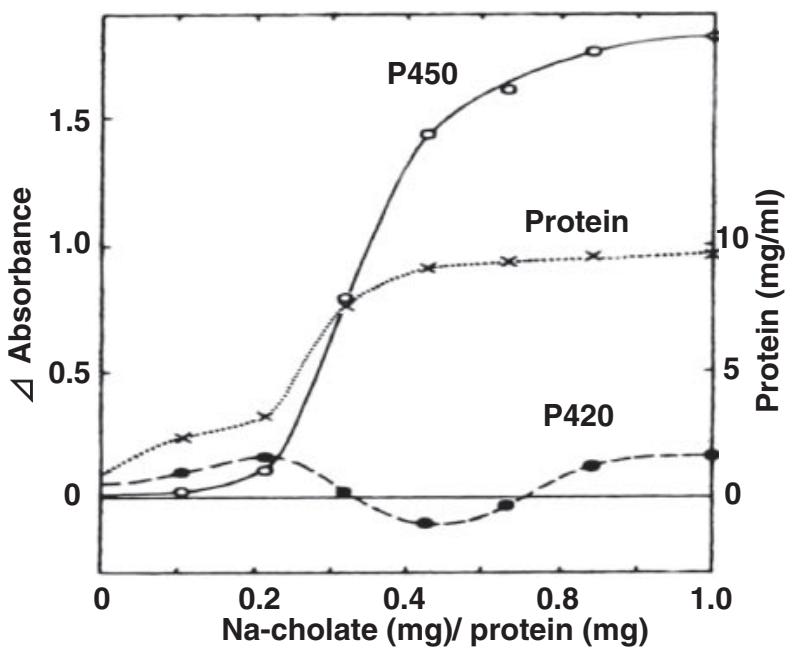

Fig. 1. Effect of concentration of cholate on the solubilization of P450 from sonicated bovine adrenocortical mitochondria. After incubation of sonicated mitochondria with Na-cholate, the samples were centrifuged at $105,000 \times \mathrm{g}$ for $90 \mathrm{~min}$ and the supernatants were analyzed. - - $-\mathrm{P} 450 ; \Delta$ Absorbance between 450 and $490 \mathrm{~nm}$ in the carbon monoxide difference spectrum. -- -: P420; $\Delta$ Absorbance between peak (420$423 \mathrm{~nm})$ and trough $(430-433 \mathrm{~nm})$ in the carbon monoxide difference spectrum. $\cdots \times \cdots \cdot$ Concentration of protein. Data from Mitani and Horie. ${ }^{43)}$ sponding to a low spin type (peaks at 417,535 , and $569 \mathrm{~nm}$ ) were lowered with concomitant increase in peaks of a high spin type (peaks at 394 and $645 \mathrm{~nm}$ ) on addition of deoxycorticosterone, a substrate for $11 \beta$-hydroxylase reaction. In contrast, peaks of a low spin type (peaks at 417, 535, and $569 \mathrm{~nm}$ ) increased by the addition of pregnenolone, a product of the cholesterol side-chain cleavage reaction. Thus, steroid-induced changes in the spin state of $\mathrm{P} 450$ were suggested, as originally reported by Narasimhulu et al. ${ }^{40)}$ in 1965 and then Schenkman et al. ${ }^{52)}$ in 1967. Subsequently, our examination on EPR spectra at $77^{\circ} \mathrm{K}$ also showed the modulation of the spin state of P450 in the presence of substrates. ${ }^{43), 47)}$ Later on, Williams-Smith and Cammack reported that such changes in spin state of $\mathrm{P} 450$ on binding with substrate result in the increase in the midpoint potential $E_{o}{ }^{\prime}$ of the heme iron of $\mathrm{P} 450^{53)}$ and facilitate the $\mathrm{P} 450$ reaction cycle. ${ }^{54)}$

Meanwhile, during the course of these studies, Omura et al. in 1966 and Simpson and Boyd in 1967 separated independently, from bovine adrenal cortex mitochondria, a steroid hydroxylation system into three components: a P450 containing particulate fraction, NADPH-diaphorase (now termed adrenodoxin reductase ${ }^{55)}$ ) and non-heme iron protein (now termed adrenodoxin $\left.{ }^{55)}\right) .{ }^{56), 57)}$ Omura et al. and Simpson and Boyd then reconstituted the steroid

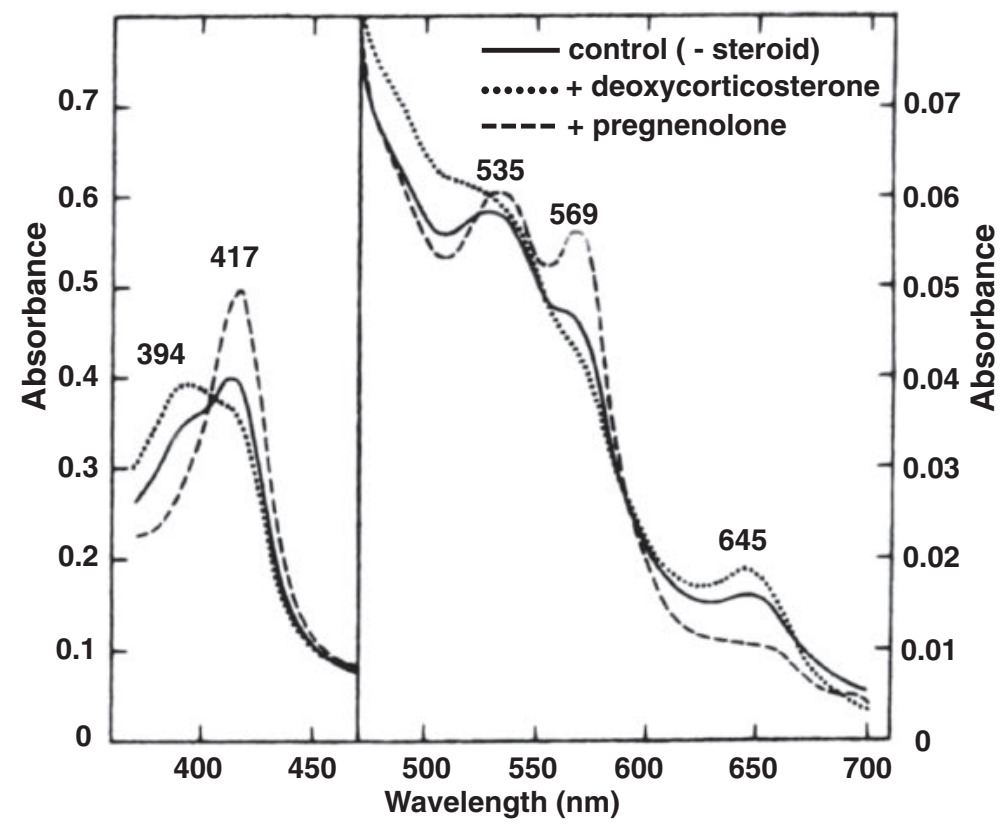

Fig. 2. Effect of steroid on the absolute absorption spectrum of the oxidized form of partially purified bovine mitochondrial P450

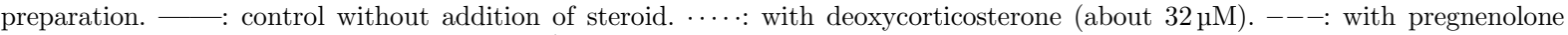
(about $32 \mu \mathrm{M}$ ). Data from Mitani and Horie. $\left.{ }^{43}\right)$ 

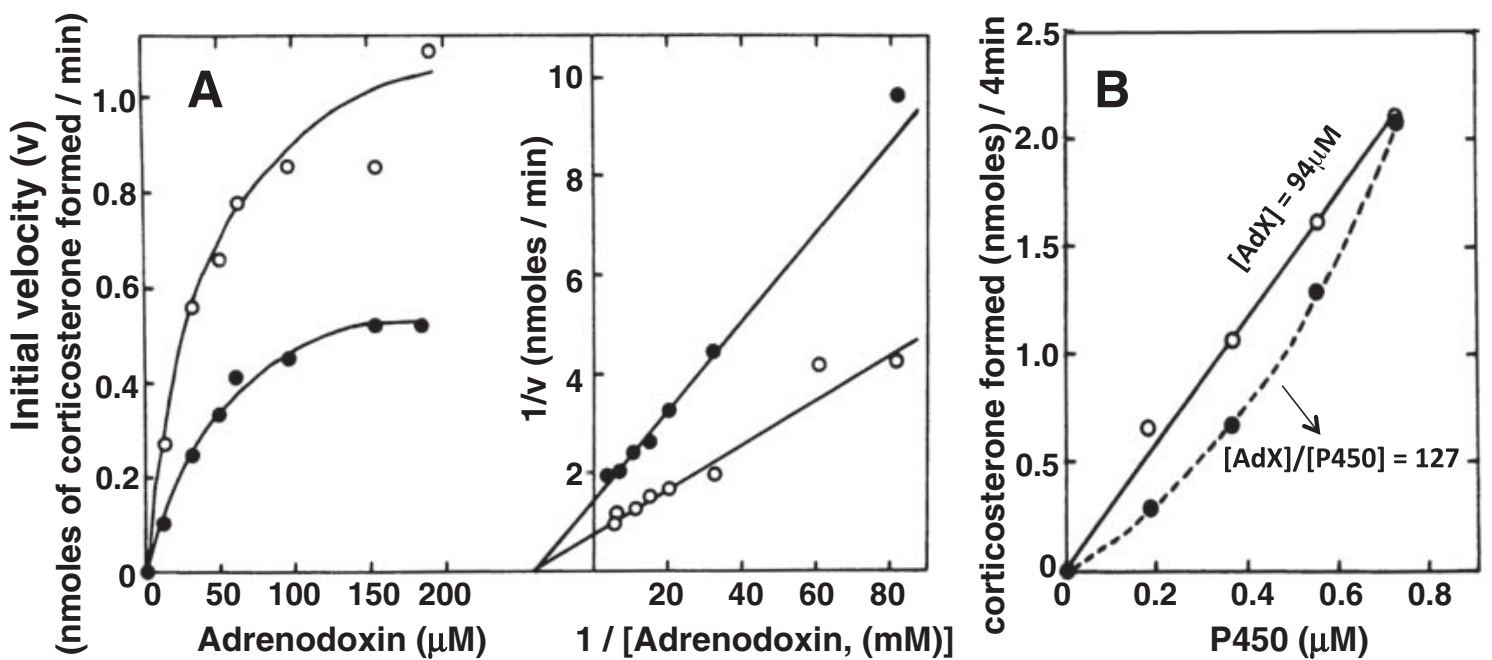

Fig. 3. Effect of adrenodoxin concentration on deoxycorticosterone $11 \beta$-hydroxylation in the reconstituted system. (A) $11 \beta$-hydroxylase reactions at various concentrations of adrenodoxin were carried out in the reconstituted $11 \beta$-hydroxylase system with $1 \mu \mathrm{M}$ or $2 \mu \mathrm{M}(\bigcirc-\bigcirc)$ of partially purified cytochrome P450. (B) The reactions were performed at a fixed concentration (94 $\mu \mathrm{M})$ of adrenodoxin $(\bigcirc-\bigcirc)$ or at a fixed molar ratio of adrenodoxin to P450 (adrenodoxin to P450=127) (----) with various concentrations of P450. AdX: adrenodoxin. Data from Mitani et al. ${ }^{49}$ )

$11 \beta$-hydroxylation system and the cholesterol sidechain cleavage system, respectively, and suggested the sequence of electron transfer from NADPH to cytochrome P450 via adrenodoxin and the reductase. In 1972, Suhara et al. obtained NADPH-adrenodoxin reductase and adrenodoxin in the pure state from bovine adrenal cortex mitochondria. ${ }^{58), 59)}$

In 1975, in order to examine the kinetic properties of the $11 \beta$-hydroxylation system, we reconstituted the system ${ }^{49}$ ) using purified adrenodoxin ${ }^{59)}$ and the reductase ${ }^{58)}$ with partially purified P450 preparation. ${ }^{43)}$ We developed a radiomicroassay method to measure the NADPH oxidation at the high level of sensitivity, that is, the amounts of NADP formed were estimated radiometrically by quantitating the ${ }^{14} \mathrm{CO}_{2}$ evolved from $\left[1-{ }^{14} \mathrm{C}\right]$ 6phosphogluconate with the aid of 6-phosphogluconate dehydrogenase. The results showed that adrenodoxin was highly autooxidizable in the reconstituted system, which confirmed Kimura's report, ${ }^{44)}$ and only small fraction of enzymatically reduced adrenodoxin was utilized for the deoxycorticosterone $11 \beta$-hydroxylation. Another point to be mentioned in this study was that an absolute concentration of adrenodoxin was essential for the optimum reaction (Fig. 3A). Therefore a linear relationship between corticosterone formation and the amount of P450 was obtained only with the excess amount of adrenodoxin in the reaction mixture, but not with the constant molar ratio of adrenodoxin to $\mathrm{P} 450$ to make a complex between them (Fig. 3B). It is now recognized that a binary complex between adrenodoxin and $\mathrm{P} 450^{60}$ ) or a ternary complex among adrenodoxin reductase, adrenodoxin and $\mathrm{P} 450^{61)}$ are not functional intermediates in electron transport in the $\mathrm{P} 450$ reaction, and adrenodoxin dimers in its oxidized state may be responsible for the reduction of $\mathrm{P} 450$, i.e., adrenodoxin dimers are reduced by the adrenodoxin reductase and serve as a mobile electron carrier, one-at-a-time, between adrenodoxin reductase and $\mathrm{P} 450$ in steroid hydroxylation systems. ${ }^{62)}$

\section{Molecular basis for the functional zonation of the adrenal cortex}

4-1) Steroid biosynthesis in the adrenal cortex and the functional zonation. In 1956, Giroud et al. provided evidence, by decapsulation of rat adrenal gland to separate the $\mathrm{zG}$ from the rest of the gland, that the principal site of aldosterone secretion is the capsular portion, i.e., $\mathrm{zG}$, and that of glucocorticoids secretion is the decapsulated portion, i.e., zFR. ${ }^{63)}$ Since aldosterone is a potent mineralocorticoid that functions in maintaining normal electrolyte balance under the control of the reninangiotensin system (RAS), while glucocorticoids regulate carbohydrate metabolism in response to signals from hypothalamus and pituitary, ${ }^{4)}$ the results showed that individual zones secrete the specific hormone of physiological importance. Such 


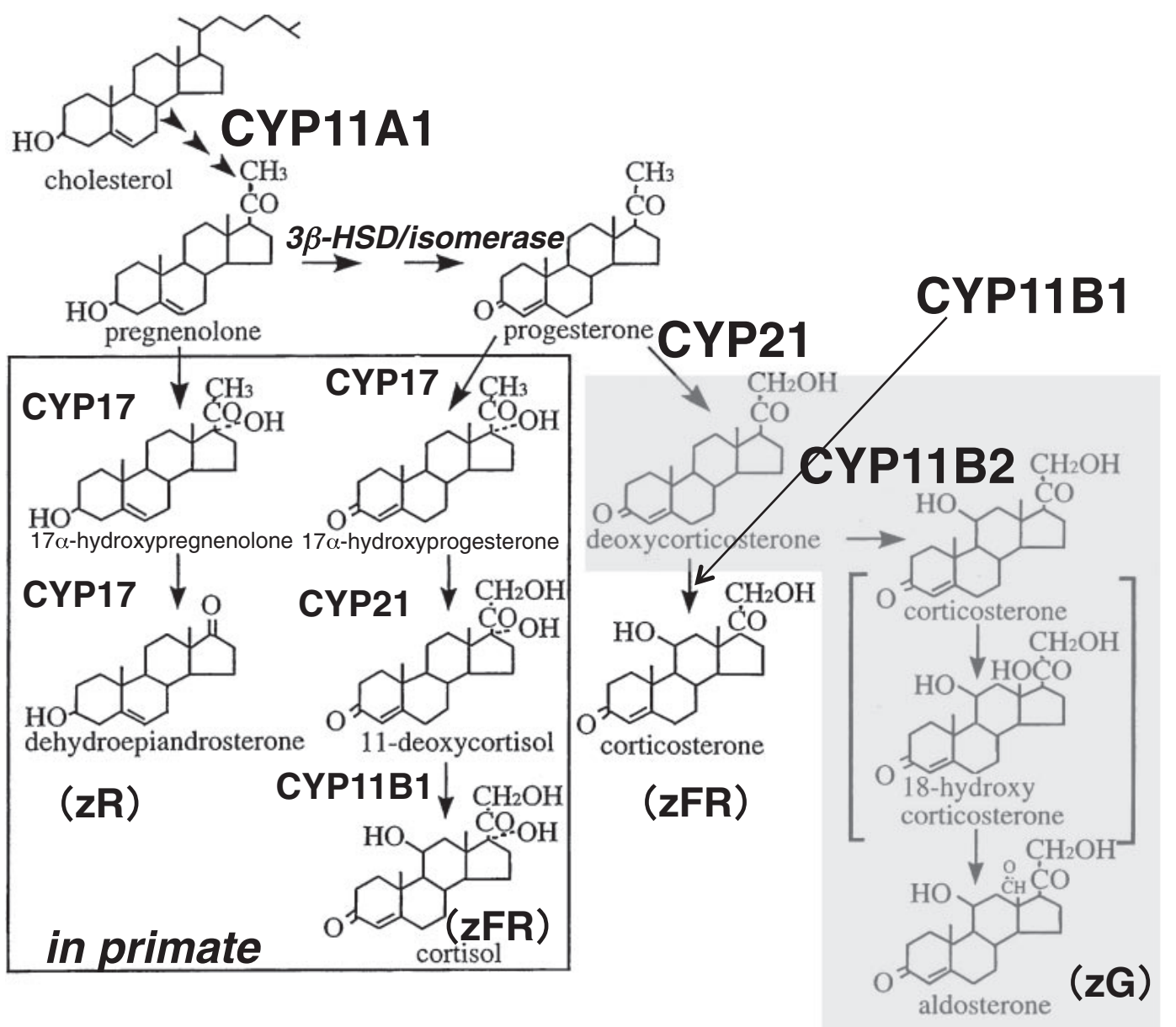

Fig. 4. Biosynthetic pathway of steroid hormones in the adrenal cortex taking cholesterol as the starting material. The gray area shows the pathway of aldosterone formation from deoxycorticosterone catalyzed by CYP11B2. Corticosterone and 18-hydroxycorticosterone are the intermediates. Reactions in the square proceed in humans and some other mammals, but not in the adrenal cortex of most rodents due to the lack of CYP17 in the adrenal cortex. zG: zona glomerulosa, zFR: zonae fasciculata-reticularis, zR: zona reticularis.

a zone-specialization in function is called "functional zonation" of the adrenal cortex. ${ }^{63), 64)}$ We have to mention, however, that the most important glucocorticoid is not the same among animals. Cortisol is the major glucocorticoid in humans and some other animals, while corticosterone is the most important glucocorticoid in rodents such as rat, mouse, rabbit, and hamster, because of the lack of $17 \alpha$-hydroxylase/ 17-20 lyase in their adrenal cortices. In addition, the $\mathrm{zR}$ of humans and some other mammals produces so-called adrenal androgens such as dehydroepiandrosterone. $^{4)}$

Figure 4 summarizes the biosynthetic pathways of adrenocortical steroid in the adrenal gland. Cholesterol is a starting steroid and converts to every major corticosteroid. As described above, all enzymes involved belong to a family of heme- containing monooxygenases ${ }^{25)}$ (or mixed-function oxidases $^{24)}$ ) called cytochrome P450 except $3 \beta$ hydroxysteroid dehydrogenase/isomerase. They may be divided into two groups depending on their intracellular localization. Those associated with the mitochondrial membrane are P450scc (now termed CYP11A ${ }^{65), 66)}$ ) responsible for cholesterol side-chain cleavage reaction, P450 $11 \beta$ (now termed CYP11B1) for steroid 11 $\beta$-hydroxylation, and P450aldo (now termed CYP11B2) for aldosterone formation. Those associated with the endoplasmic reticulum (microsome) membrane are $\mathrm{P}_{450} 0_{17 \alpha}$ (now termed CYP17) for steroid $17 \alpha$-hydroxylation and C17-C20 bond cleavage, $\mathrm{P} 450_{\mathrm{C} 21}$ (now termed CYP21) for steroid 21-hydroxylation, and $3 \beta$-hydroxysteroid dehydrogenase/isomerase. ${ }^{37), 67)}$ Thus, the metabolic intermediates in the pathways must move in and out of 
the mitochondria and endoplasmic reticulum during the biosynthesis.

Among these hydroxylation enzymes, the following enzymes had been highly purified by early 1980s (reviewed in ref. 36); CYP11A1 and CYP11B1 from bovine adrenal cortex mitochondria by Takemori et al. in 1975, ${ }^{45), 46)}$ CYP21 from bovine adrenal cortex microsomes by Kominami et al. in 1980, ${ }^{68)}$ and CYP17 from guinea pig adrenal cortex microsomes by Kominami et al. in 1982. ${ }^{69)}$ Surprisingly, although the highly purified CYP11B1 from bovine adrenal cortex mitochondria was a single entity in terms of protein chemistry, it catalyzed aldosterone formation as well as $11 \beta$-hydroxylation. ${ }^{70)}$ In 1989 , we attempted to separate the enzyme catalyzing aldosterone formation from that catalyzing $11 \beta$ hydroxylation in bovine adrenal cortex, and obtained two distinct forms of CYP11B1 with apparent molecular weights of $48.5 \mathrm{kDa}$ and $49.5 \mathrm{kDa}^{71)}$ However, both forms of CYP11B1 were capable of catalyzing aldosterone formation as well as the $11 \beta$ and 18-hydroxylation of 11-deoxycorticosterone, although the intensities of those enzymatic activities of the two forms were slightly different. ${ }^{71)}$ It seemed unlikely that only one of the forms functions specifically in aldosterone synthesis in $\mathrm{zG}$, while the other functions specifically in glucocorticoid production in zFR, since both forms are distributed almost equally throughout the three zones of the bovine adrenal cortex. Later in 1992, Ikushiro et al. reported that aldosterone synthesizing activity of CYP11B1 was suppressed by interaction with CYP11A1 in bovine adrenal cortex. ${ }^{72}$ In bovine adrenal cortex, the zG-specific aldosterone secretion and the zFRspecific glucocorticoid secretion might be induced by differences in the interaction of CYP11B1 with CYP11A1, as a modulator, of inner mitochondrial membranes in each zone. However, the true mechanism of action remains to be clarified.

4-2) Purification of aldosterone synthase, CYP11B2, from the rat adrenal cortex. The enzyme responsible for the final step of aldosterone biosynthesis (see Fig. 4), on the other hand, was not identified or isolated until the end of the 1980s. In 1987, Lauber et al. identified the aldosterone synthase in the $z G$ of rat adrenal cortex. ${ }^{73)}$ They used mitochondria from the capsular portion of sodiumdeficient and potassium-repleted rats, ${ }^{74}$ in which the conversion of corticosterone to 18-hydroxycorticosterone and aldosterone proceeded at markedly higher rates than in mitochondria from the capsular portion of adrenals of sodium-repleted and potassium-defi-

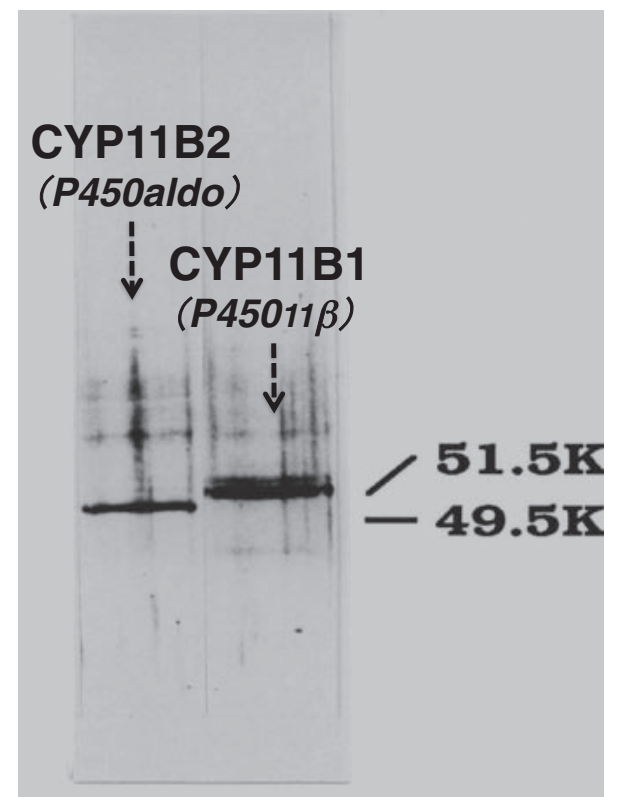

Fig. 5. SDS-PAGE analysis of CYP11B2 and CYP11B1 purified from rat adrenal gland. The bands were visualized by silver staining. Apparent molecular weights of CYP11B2 and CYP11B1 determined from the comparison of the protein markers were $49.5 \mathrm{kDa}$ and $51.5 \mathrm{kDa}$, respectively. Data from Ogishima et al..$^{75)}$

cient rats without difference in the $11 \beta$-hydroxylase activity.

The purification of the aldosterone synthase, CYP11B2, was accomplished by Ogishima, Mitani and Ishimura in 1989 from zG of the adrenal cortex of sodium-deficient and potassium-repleted rats. ${ }^{75)}$ The highly purified CYP11B2 (49.5 kDa) was distinguishable protein chemically, genetically and immunochemically from CYP11B1 $(51.5 \mathrm{kDa})$ purified from zFR of the same rat (Fig. 5). Purified CYP11B2 catalyzed the multi-hydroxylation reactions of the substrate (11-deoxycorticosterone) giving corticosterone, 18-hydroxydeoxycorticosterone, 18-hydroxycorticosterone, and significant amount of aldosterone as products, while purified CYP11B1 catalyzed only $11 \beta$ - and 18-hydroxylations of the same substrate to yield corticosterone and 18-hydroxydeoxycorticosterone, respectively (refer to Fig. 4). The existence of CYP11B2 in the rat adrenal cortex but not in the bovine adrenal cortex as described in the above section led to the hypothesis that at least two different types or modes of corticosteroidogenesis exist in animals: adrenal glands with CYP11B2 that catalyzes aldosterone formation (a rodent type), and adrenal glands without CYP11B2, where CYP11B1 catalyzes aldosterone formation in addition to 


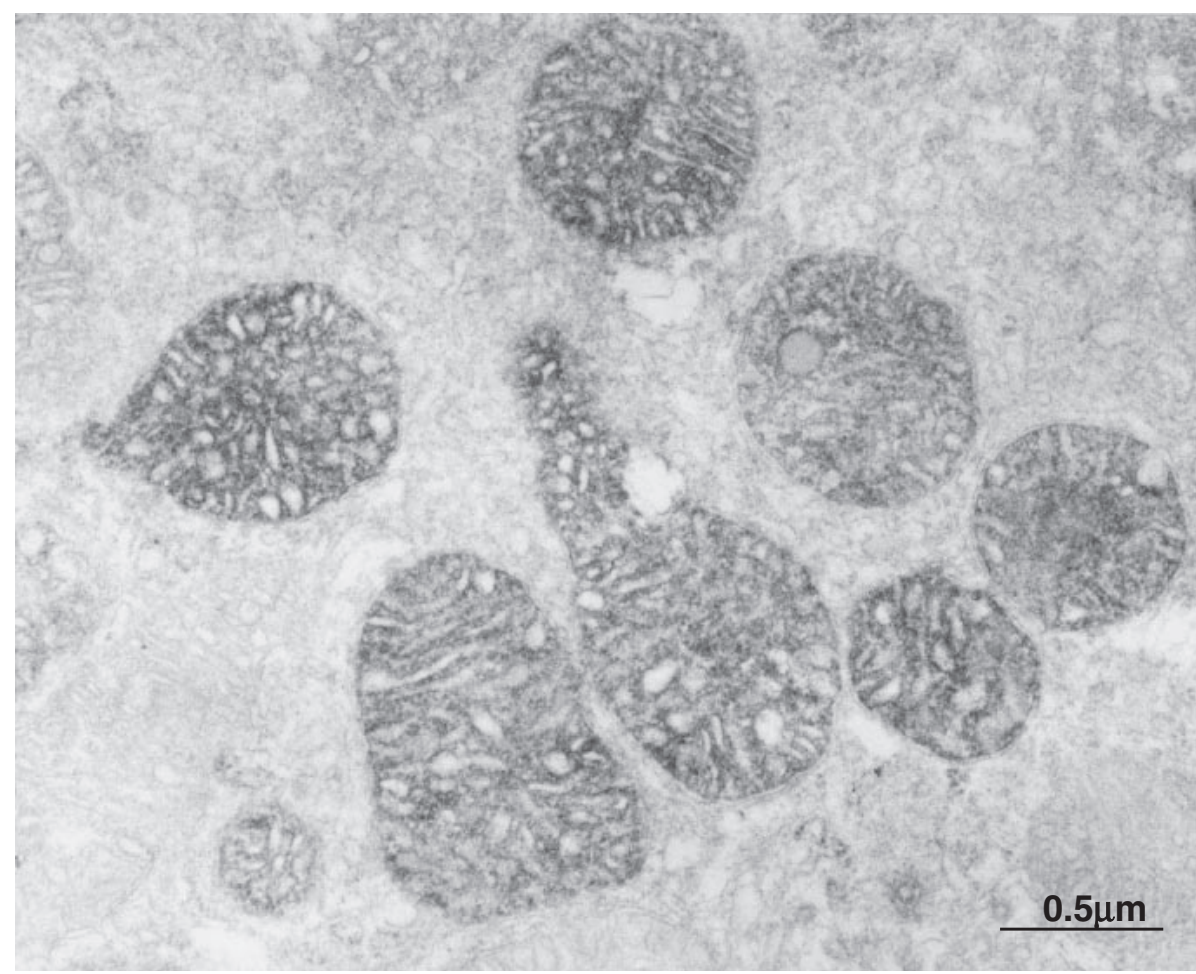

Fig. 6. Electron microscopic view of the immunocytochemical staining for CYP11B1 localization in a $\mathrm{zF}$ cell of bovine adrenal gland. The section was treated directly with peroxidase-labeled anti-bovine CYP11B1 (Fab'). CYP11B1 (in black) is located mainly on the surfaces of the inner mitochondrial membranes along with tubulovesicular cristae. Data from Mitani et al. ${ }^{77)}$

glucocorticoid formation (a cattle type). Our group also purified CYP11B2 from adrenals of patient with primary aldosteronism and suggested that human corticosteroidogenesis resembles that of the rat (the first type described above) and differs from that of the cattle (the second type described above). ${ }^{76}$ )

\section{Immunohistochemical localization of steroid hydroxylases and establishment \\ of the molecular basis for the functional zonation of the adrenal cortex}

In 1982 , to understand more clearly steroidogenesis in the adrenal cortex, we attempted to localize CYP11A1 and CYP11B1 immunohistochemically in bovine adrenal glands. ${ }^{77)}$ Antibodies against purified bovine CYP11A1 and CYP11B1 were used for the direct peroxidase-labeled antibody method. At the light microscopic level, parenchymal cells of the zFR stained heavily for both cytochromes (CYPs), while those of zG stained lightly for both, reflecting the content of the enzyme. At the electron microscopic level, these two cytochromes were associated with the matrix side of the inner mitochondrial membranes including the tubulovesicular cristae (Fig. 6). Since P450-reducing components, adrenodoxin and the reductase, were localized in a similar manner in the bovine adrenal gland, ${ }^{78)}$ our results indicated for the first time that steroid monooxygenase systems exist at the matrix side of the inner mitochondrial membrane (refer to ref. 79).

Subsequently, in 1992, our efforts to localize CYP11B2 and CYP11B1 in rat adrenal glands were successful. ${ }^{80), 81)}$ The homology between purified rat CYP11B2 and rat CYP11B1 is approximately $83 \%$ in the amino acid sequence deduced from their cDNA clones. Therefore, we selected peptide sequence with highly variable regions, i.e., 151-163 residues for CYP11B2 and 248-259 residues for CYP11B1, and used each sequence for making specific antibodies. Figure 7 shows double immunohistochemical staining of the rat adrenal gland with those antibodies (A: the adrenal section from a rat fed on a control diet, B: the adrenal section from a rat fed on a Na-deficient diet). CYP11B2 (colored in blue) is confined strictly to the $\mathrm{zG}$, while CYP11B1 (colored in brown) is present largely in the $\mathrm{zF}$ and sparsely in the $\mathrm{zR}$, but not in the $\mathrm{zG}$ of rats under both normal and Na-deficient conditions. Neither enzyme is 
A

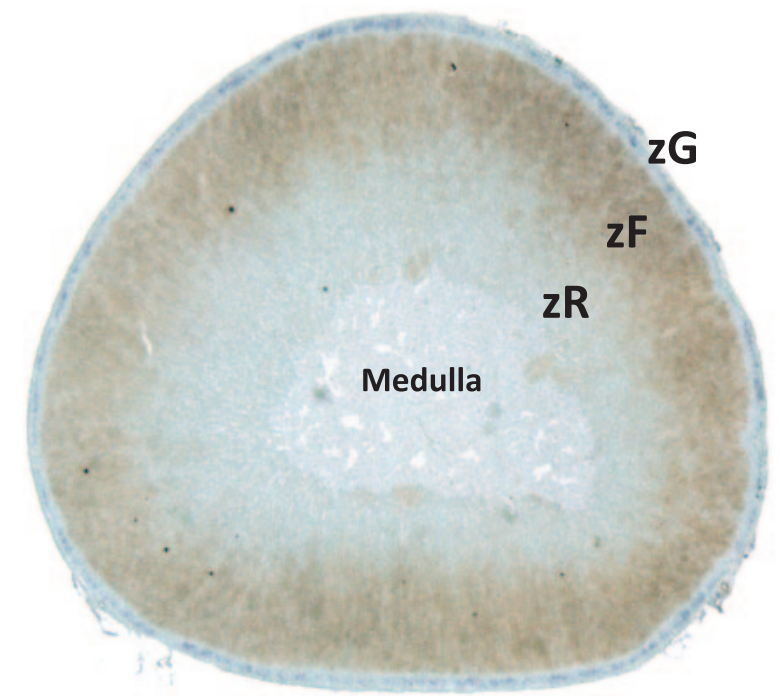

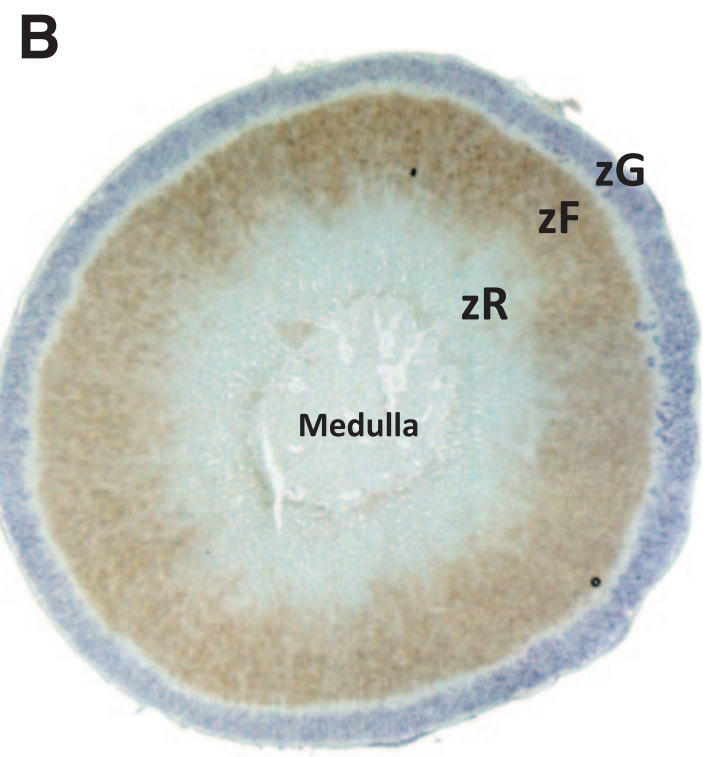

Fig. 7. Localization of CYP11B2 and CYP11B1 in the rat adrenal gland by immunohistochemical staining. A: An adrenal section from a rat fed on a control diet stained with the anti-rat CYP11B2 and the anti-rat CYP11B1 antibodies simultaneously. B: An adrenal section from a rat fed on a Na-deficient diet for 20 days stained with the anti-rat CYP11B2 and the anti-rat CYP11B1 antibodies simultaneously. In both figures, blue and brown colors show the presence of CYP11B2 and CYP11B1, respectively. Nuclei were poststained with methyl green. zG: zona glomerulosa, zF: zona fasciculata, zR: zona reticularis. Data from Mitani et al. ${ }^{81)}$

detected in the medulla or the capsule. This finding, together with the previous findings that CYP17 was localized in the zFR, ${ }^{82), 83)}$ established the molecular basis for the functional zonation in adrenocortical steroidogenesis.

\section{An undifferentiated cell zone between $z G$} and $\mathrm{zF}$ and its possible functional significance relating to the development and maintenance of the rat adrenal gland

6-1) Discovery of the undifferentiated cell zone between $\mathrm{zG}$ and $\mathrm{zF}$ of the rat adrenal cortex. The adrenal cortex consists of three morphologically and functionally distinct zones: the $\mathrm{zG}, \mathrm{zF}$ and $\mathrm{zR}$. In 1994, however, we noticed the presence of a 4 th zone between $\mathrm{zG}$ and $\mathrm{zF}$ when we performed double immunohistochemical staining of adult rat adrenal gland with anti-CYP11B1 and anti-CYP11B2 antibodies. ${ }^{81)}$ Figures 7 and 8 show the new zone (in white) consisting of five to six cell layers between CYP11B2-positive zG (colored in blue) and CYP11B1-positive zF (colored in brown). The observation that the 4th zone has no immunoreactivity with anti-CYP11B2 and anti-CYP11B1 antibodies and appears like a white ring surrounding $\mathrm{zF}$ (Fig. 7) suggests the absence of both CYP11B2 and CYP11B1. Since adrenal glands of animals such as rat, mouse, rabbit, and hamster are devoid of
CYP17, which catalyzes the formation of androgen synthesis in the $\mathrm{zR}$ of mammals, the newly found zone can be characterized as lacking adrenal androgen synthesis as well. Thus, the cells in this zone appeared to have no significant endocrine function specific to zones of the adrenal cortex and, therefore, could be regarded as undifferentiated cells with respect to corticosteroidogenesis. We designated the zone as the undifferentiated cell zone $(\mathrm{zU})$ and considered it a stem/progenitor cell zone in the adrenal cortex. Cells in this zone are parenchymal cells and are shown immunohistochemically to express transcription factor $\mathrm{SF}-1 / \mathrm{Ad} 4 \mathrm{BP},{ }^{84)}$ and other marker proteins present in adrenocortical cells, including CYP11A1, CYP21, 3 $\beta$-hydroxysteroid dehydrogenase/isomerase, and a $\mathrm{P} 450$ reducing system.

The number of the cells per unit area in $\mathrm{zU}$ is greater (Figs. 8A and 8B) and lipid contents are smaller than those in the other cortical zones. In addition, some differences in capillary architecture visualized as alkaline phosphatase activity staining are noticed (Fig. 8C). These histological features are similar to those of formerly reported zones, such as the "sudanophobe zone", 85) "zona intermedia",86) or "transitional zone", 87 ) and we were able to identify the functional meaning by immunohistochemical methods. However, it should be emphasized here that the sudanophobe zone has not always been 


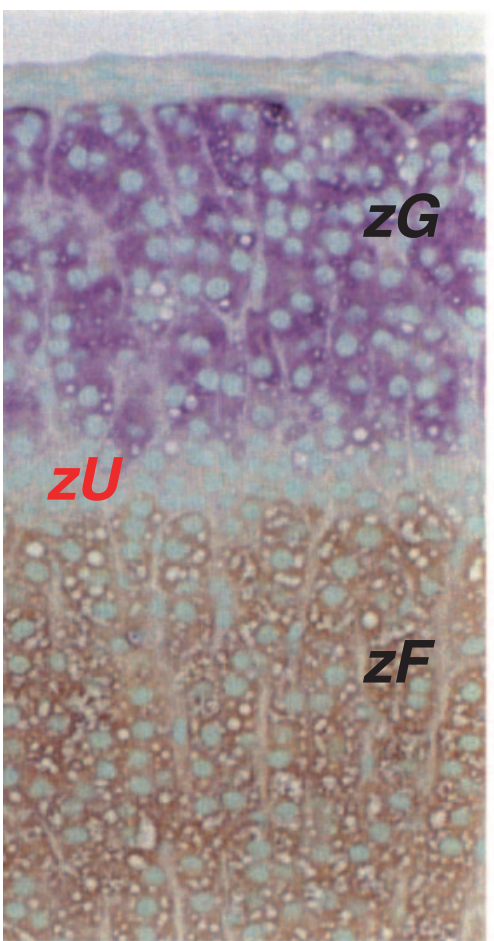

A. CYP11B2 \& CYP11B1

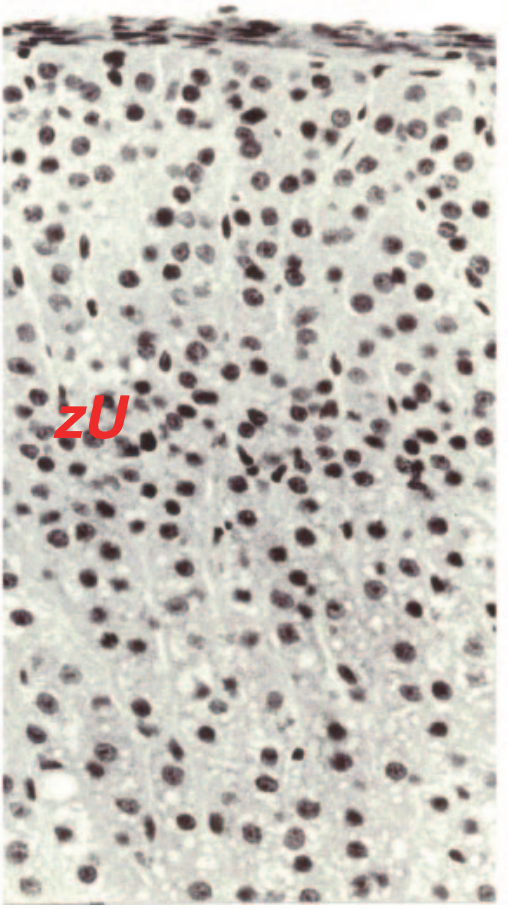

B. nuclei

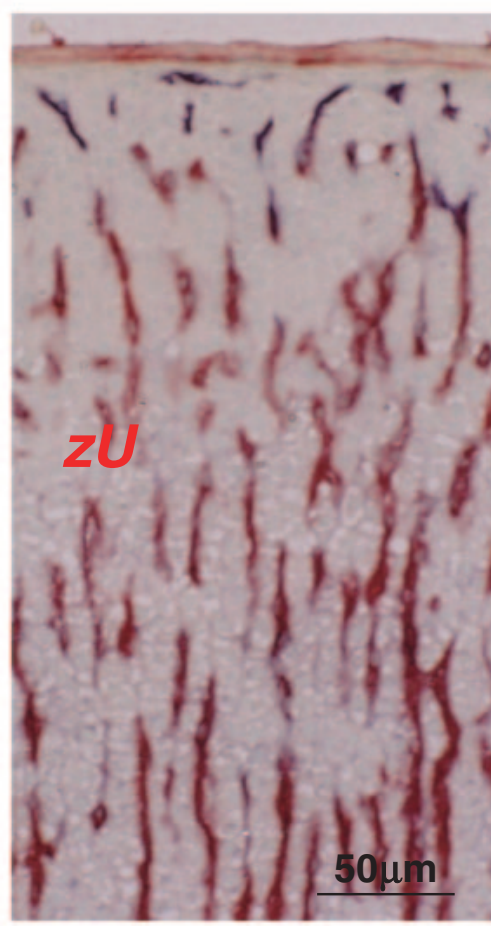

C. microvasculature

Fig. 8. Histological features of the undifferentiated cell zone (zU). The adrenal sections from rats fed on Na-deficient diet for 20 days were used for the staining. A: An adrenal section stained with anti-rat CYP11B2 (in blue) and anti-rat CYP11B1 (in brown) antibodies simultaneously. Nuclei were poststained with methyl green. B: Nuclei in adrenocortical cells stained with hematoxylin (in black). C: Alkaline phosphatase activities in the adrenal cortex visualized enzyme-histochemically to show the localization of microvasculatures (in dark red). zG: zona glomerulosa, zF: zona fasciculata, zU: undifferentiated cell zone. Data from Mitani et $_{\text {al. }}{ }^{81 \text { ) }}$

demonstrated among animal adrenals, ${ }^{86)}$ e.g. the zone was hardly recognized in mouse, pig, ox and human adrenal glands, and, even in rats, there was a strain difference with Wistar rat having $z U$ with considerably thinner cell width than that of SpragueDawley rats, which we used in our study. Unfortunately, these differences sometimes led to confusion in the comparison of data from various groups.

6-2) Proliferative cells in and around $\mathrm{z} U$ and the circadian rhythm. In an attempt to explore the possible function of $\mathrm{zU}$, replicating adrenal cells were examined by demonstrating 5 -bromo- 2 '-deoxyuridine (BrdU) incorporation into the nuclear DNA of Sphase cells and proliferating cell nuclear antigen (PCNA) immunohistochemically. BrdU was administered to rats intraperitoneally at $1 \mathrm{~h}$ prior to sacrifice. The results indicated that the S-phase cells localized mainly in two regions of the cortex, the innermost portion of $\mathrm{zG}$ and the outermost portion of $\mathrm{zF}$, which are adjacent to the outer and inner edges, respectively, of zU (Fig. 9A). ${ }^{81), 88)}$ Since S-phase cells and PCNA-positive cells were observed only scarcely in the other regions of the adrenal cortex, $\mathrm{z} U$ and its surroundings were thought to be the site of cell proliferation in the adult rat adrenal cortex.

During this study, however, we noticed that the total number of replicating cells in the adrenal cortex was dependent on the time of BrdU injection. Therefore, we examined the temporal and spatial distributions of BrdU-positive cells in the adrenal cortex. ${ }^{88)}$ Although the BrdU-positive S-phase cells were observed throughout the day in two regions as described above, the number of BrdU-positive cells exhibited a marked fluctuation depending on time of day. A burst of cell proliferation was found to occur at 3-4:00 a.m. with a minimum at around noon in the outermost portion of zF (Fig. 10A). Further examination showed that the prominent rise in the plasma adrenocorticotropic hormone (ACTH) concentration preceded such a burst of cell proliferation by about $4 \mathrm{~h}$ (Fig. 10A). By increasing the plasma ACTH concentration by administration of ACTH or metyrapone, an inhibitor for glucocorticoid biosynthesis, the rhythm of cell replication was found to shift 

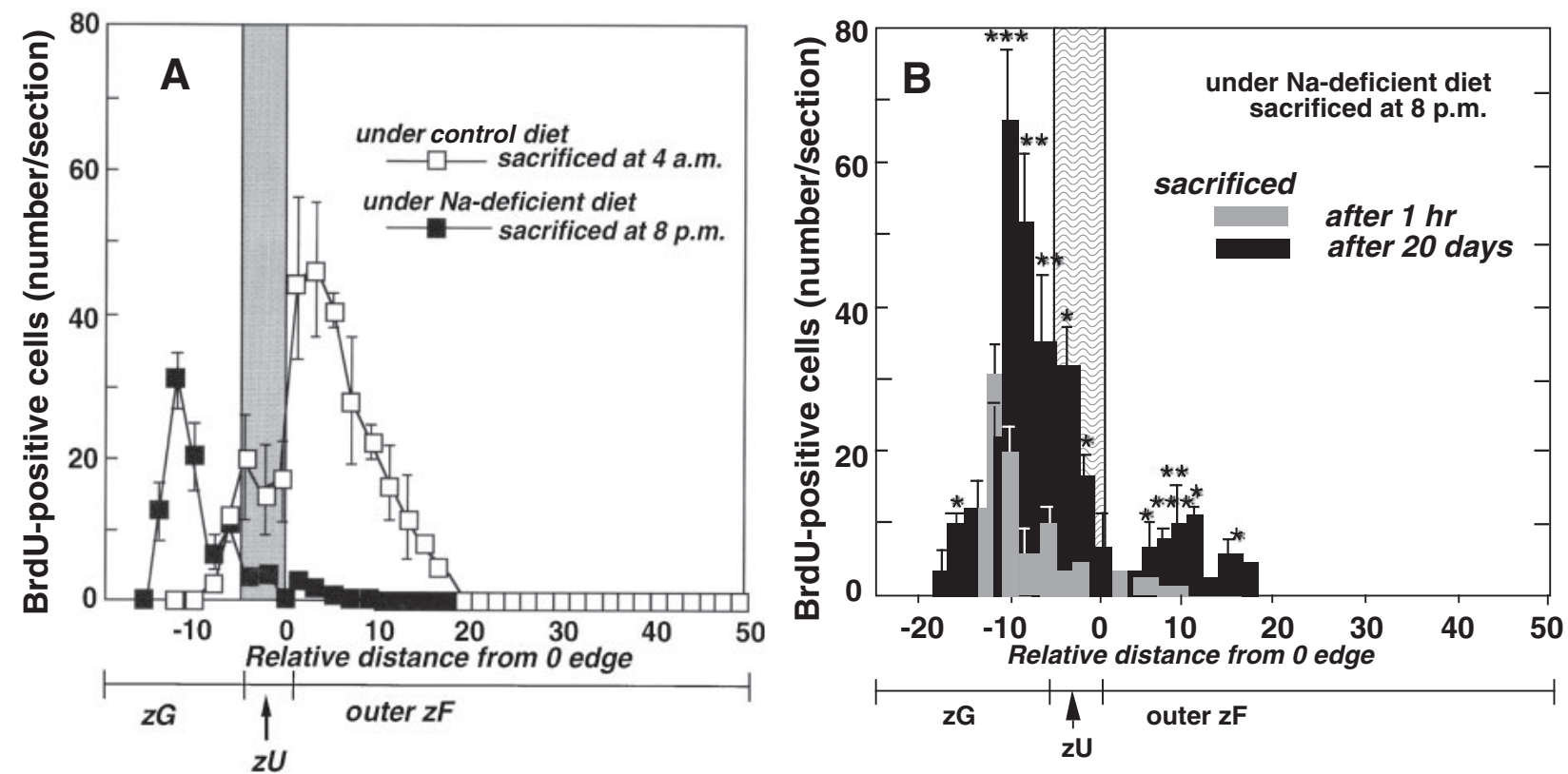

Fig. 9. Spatial distribution of BrdU-positive cells and the movement in the adrenal cortex. (A) Spatial distribution of BrdU-positive cells in the adrenal cortex. $\square$, BrdU-positive cells in the adrenal cortex from rats fed on a control diet for 10 days and sacrificed at 4:00 a.m. 口, BrdU-positive cells in the adrenal cortex from rats fed on a Na-deficient diet for 10 days and sacrificed at 8:00 p.m. In both rats, BrdU was injected at $1 \mathrm{~h}$ before sacrifice. (B) Behavior of BrdU-positive cells under Na-deficiency. Rats fed on a Na-deficient diet for 10 days were injected BrdU at 7:00 p.m. and sacrificed at $1 \mathrm{~h}$ (gray column) or at the 20th day (black column) after the injection. ${ }^{*} P<0.05,{ }^{* *} P<0.01,{ }^{* * *} P<0.001$ : data obtained at $1 \mathrm{~h} v s$. at the 20 th day in a comparable region. Numbers on the $X$-axis (relative distance from 0 edge) show the distance (cell layer) from " 0 ", which is defined as the position of the innermost cell layer of the undifferentiated cell zone $(\mathrm{zU})$. Values are mean \pm SEM. $\mathrm{zG}$ : zona glomerulosa, $\mathrm{zF}$ : zona fasciculata, zU: undifferentiated cell zone. Data from Miyamoto et al..$^{88), 89)}$ and Mitani et al. ${ }^{90)}$

accordingly. The mechanism underlying the effect of ACTH on the wave of cell proliferation, however, is not clear at present. Elevation in plasma $\mathrm{ACTH}$ concentration, on the other hand, had little effect on cell proliferation at the innermost portion of $\mathrm{zG}$, suggesting that cytogenesis in this region was regulated by a different mechanism from that in the ACTH-regulated region. A significant increase in the number of S-phase cells in the innermost portion of zG was observed in rats fed with a Na-deficient diet. $^{89)-91)}$ The peak was at around 8:00 p.m. (Fig. 10B). It is well known that Na-deficiency results in activation of the renin-angiotensin system (RAS), which, in turn, increases the proliferation of zG cells along with high expression of CYP11B2. Under a control diet, the number of replicating cells in the innermost portion of $\mathrm{zG}$ was considerably smaller than that in the outermost portion of $\mathrm{zF}$, and the circadian rhythm was hardly observable (Fig. 10B). These observations demonstrate that cell replication in the two regions around $\mathrm{zU}$, outer and inner edges of $\mathrm{zU}$, are regulated differently by RAS and ACTH, respectively.
The behavior of BrdU-positive cells was examined from $1 \mathrm{~h}$ to 20 days after the injection of BrdU. ${ }^{89), 90)}$ Under normal hormonal conditions, BrdU-positive cells were found mostly in the outermost portion of zF at $1 \mathrm{~h}$ later as mentioned already (Fig. 9A). After 20 days, those positive cells were found to shift to the inner portion of $\mathrm{zF}$, indicating that the BrdU-positive cells migrated centripetally. ${ }^{90), 91)}$ The number of BrdU-positive cells increased by about 3 -fold after 20 days, suggesting that the cells divided further during migration. Under Nadeficiency, BrdU-positive cells were found mostly in the innermost portion of $\mathrm{zG}$ at $1 \mathrm{~h}$ later (Figs. 9A and $9 \mathrm{~B}$ ). Contrary to the centripetal migration of replicating cells from the outermost portion of $\mathrm{zF}$ under normal conditions, BrdU-positive cells in the innermost portion of $\mathrm{zG}$ under Na-deficiency did not migrate over $\mathrm{zU}$ even at the 20th day after injection, and instead moved toward the periphery of $\mathrm{zG}$ (Fig. 9B). The number of cells increased by about 3 -fold, therefore, they further proliferated during that time. Thus, BrdU-positive cells in the two regions around $\mathrm{zU}$ seemed to behave differently, i.e., 

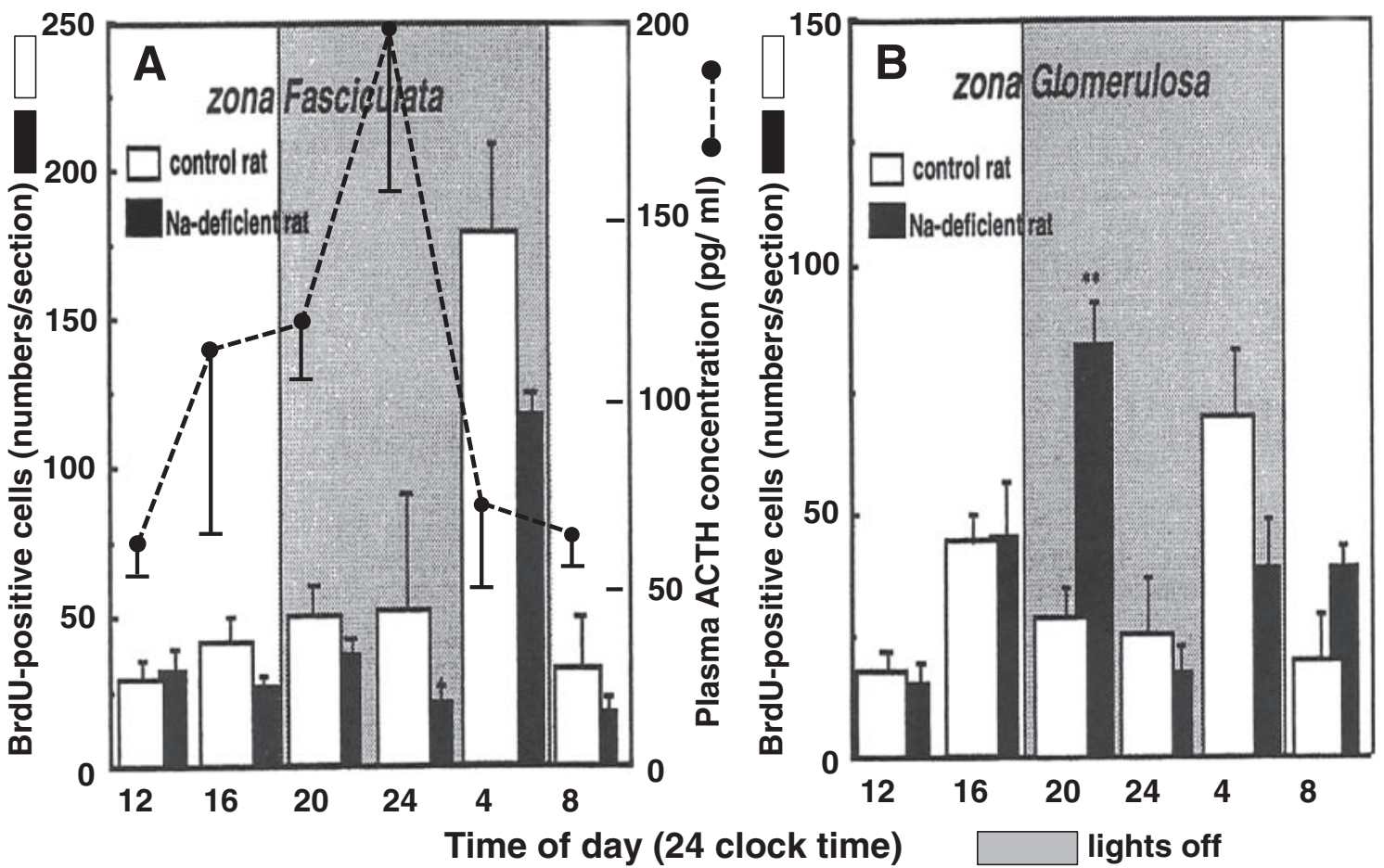

Fig. 10. Circadian rhythm in the cell proliferation in the adrenal cortex during a 24-hours period. (A) Circadian rhythm in the cell proliferation in zF of rats fed on either control $(\square)$ or Na-deficient $(\square)$ diets for 10 days. The total numbers of BrdU-positive cells/ section were plotted as a function of the time of a day. ACTH concentrations (---) in plasma of rats fed on a control diet were also plotted as a function of the time of a day. (B) Circadian rhythm in the cell proliferation in zG of rats fed on either control ( $\square$ ) or Na-deficient ( $\square$ ) diets for 10 days. The total numbers of BrdU-positive cells/section were plotted as a function of the time of a day. Values are mean \pm SEM. $\left({ }^{* *} \mathrm{p}<0.01\right.$; data on Na-deficient rats $v s$ control rat at 8:00 p.m.). Refer to data from Miyamoto et al. ${ }^{88), 89)}$ and Mitani et al. ${ }^{90)}$

BrdU-labeled cells in the outermost portion of $\mathrm{zF}$ migrate centripetally with days, while those in the innermost portion of zG migrate centrifugally. ${ }^{89), 90)}$ Bidirectional movement of stem/progenitor cells has been also observed in the small intestine. ${ }^{92), 93)}$

6-3) zU in regeneration of the adrenal gland after transplantation and enucleation. Autoplastic transplant of the adrenal gland was demonstrated by Jaffe and Plavska as early as $1926 .{ }^{94)}$ Two glands removed from a rat were cut in half and the four parts were immediately transplanted into pockets between the fascia and abdominal muscle of the bilateral adrenalectomized rat. In 3 or 4 weeks, the transplants regenerated as highly vascularized masses of cortical tissue, with the three cortical layers. Later experiments suggested that only small fragments of capsular tissue containing zG cells were necessary for the successful transplantation of the adrenal gland, because $\mathrm{zG}$ was thought to retain some characteristics of stem cells. ${ }^{95), 96)}$ Transplantation of primary bovine adrenocortical cells beneath the kidney capsule of bilateral adrenalectomized immunodefi- cient (scid) mice prevented the adrenal insufficiency in the absence of sodium supplementation. ${ }^{97}$ )

The criteria of studies on the regeneration of the adrenal cortex after transplantation or enucleation $^{98), 99)}$ were based mostly on histological, cytochemical and physiological features of the adrenal cortex. Therefore in 1995, we investigated the regeneration process of the adrenal cortex after bilateral enucleation by immunohistochemical localization of the zone-specific steroid hydroxylating enzymes, CYP11B2 in zG and CYP11B1 in zFR, and PCNA-containing cells (S-phase cells). ${ }^{100), 101)}$ In order to enucleate the adrenal gland, each adrenal gland was exposed through the dorsal route and its capsule was sliced open at one site. The opposite site was then slightly pressed with forceps to extrude the solid content inside, and the content was discarded. Because of the fragility of $\mathrm{zU}, \mathrm{zG}$ could be easily separated along $\mathrm{zU}$ from the other cortical zones, adhering to the capsule. The capsular portion was then restored to position in order to permit regeneration. ${ }^{102)}$ Afterwards rats were maintained on a 


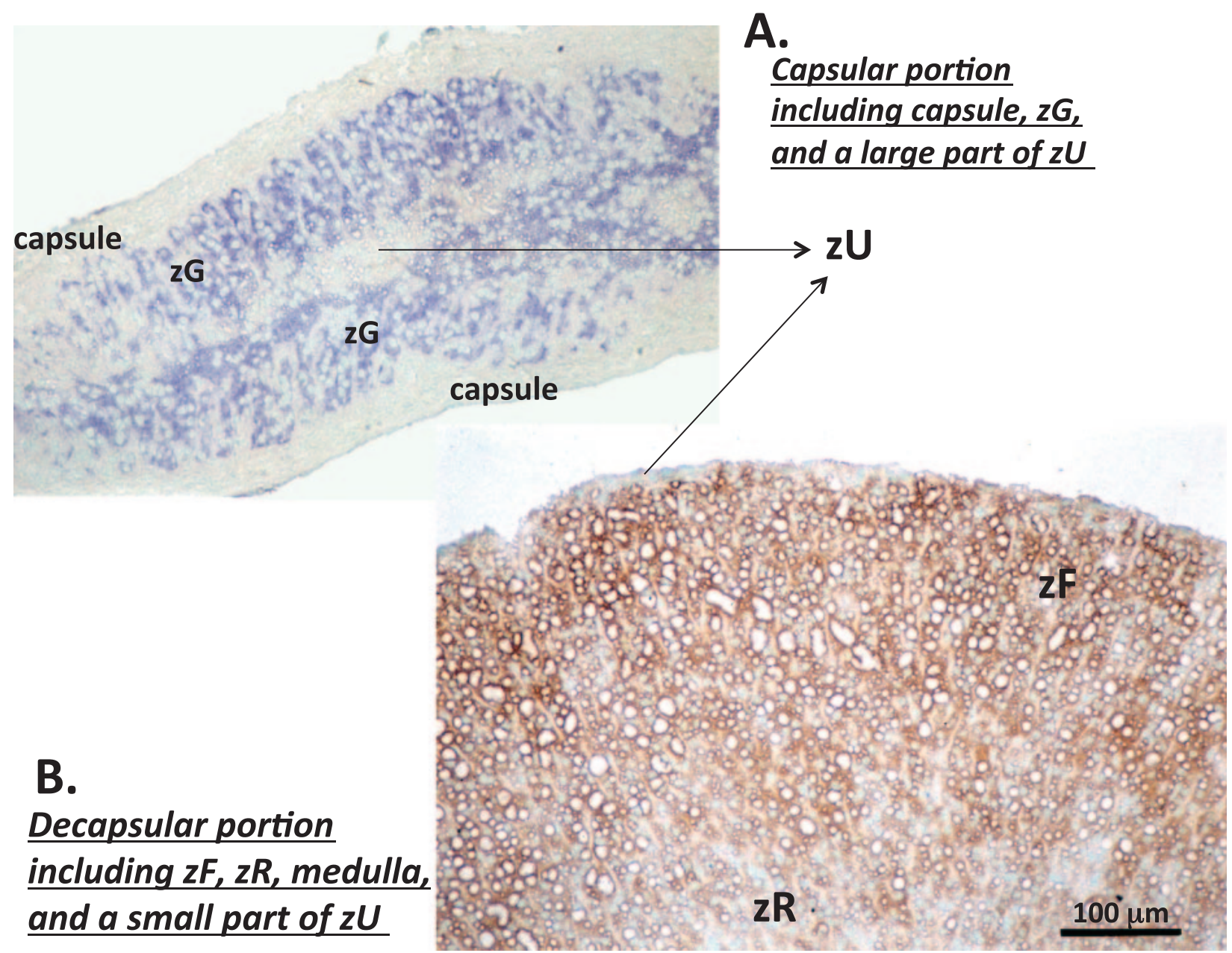

Fig. 11. Capsular and decapsular portion after the enucleation of the adrenal gland. The enucleation of the adrenal gland was performed using rats fed on Na-deficient diet for 20 days in order to detect zG clearly as CYP11B2-expressing zone. After the enucleation, the capsular and the decapsular portion were stained using anti-rat CYP11B2 and anti-rat CYP11B1 antibodies simultaneously. A: The capsular portion of the adrenal gland. Note that, on the plate, a section of the capsular portion is bent, and one inner edge of zU is located side by side with another edge of zU. B: The decapsular portion of the adrenal gland. In both figures, blue and brown colors show the presence of CYP11B2 and CYP11B1, respectively. Nuclei were poststained with methyl green. $\mathrm{zG}$ : zona glomerulosa, zF: zona fasciculata, zR: zona reticularis, zU: undifferentiated cell zone. Refer to data from Mitani et al. ${ }^{100)}$ and Mitani and Ishimura. ${ }^{101)}$

normal or a Na-deficient diet. It should be noticed here that the decapsulated portion discarded had $\mathrm{zF}$ (visualized with CYP11B1 stained in brown color in Fig. 11B), zR, the medulla, and a small part of $z U$, while the capsular portion remaining in the body contained the capsule and $\mathrm{zG}$ (visualized with CYP11B2 stained in blue color in Fig. 11A), and also contained a large portion of $\mathrm{zU}$ (in white in Fig. 11A). On the second day after enucleation, the hematoxylin-eosin stained section of the adrenal gland revealed that the whole gland was filled with a large hemorrhagic coagulum containing a small amount of surviving cortical cells at the periphery. On the 20th day, however, the gland was mostly occupied by regenerated cortical cells, where restoration of the three cortical zones was recognized with appearance of $\mathrm{zU}$ between $\mathrm{zG}$ and $\mathrm{zF}$. Double immunostaining of CYP11B2 and CYP11B1 demonstrated a significant number of CYP11B1-containing cells in zF and a few of those in zR, and CYP11B2containing cells in the $\mathrm{zG}$ portion. Although replicating cells observed as PCNA-positive cells were present throughout the regenerating cortex until 1 week after the enucleation, they were concentrated in and around $\mathrm{zU}$ with restoration of the three cortical zones. ${ }^{100), 101)}$ These observations suggest that $\mathrm{zU}$ in the capsular portion was related to the regeneration of the adrenal cortex. A quantitative analysis of 
zone-specific proliferation after the enucleation was performed by Engeland's group in 2005. ${ }^{103)}$

6-4) zU during the development of the adrenal gland. In 1997, we further examined the behavior of $\mathrm{zU}$ cells during development of the rat adrenal gland. ${ }^{104), 105)}$ At around the time of birth, medullary cells intermingled with cortical cells at fetal stages gathered in the center of the adrenal gland, and the zonation including $\mathrm{zU}$ became distinct. On the other hand, DNA-synthesizing cells (BrdUpositive cells) were found scattered throughout the gland at fetal stages, where they proliferated without significant migration. After birth, BrdU-positive cells were localized around $\mathrm{zU}$ between the established $\mathrm{zG}$ and $\mathrm{zF}$, and then migrated centripetally with days. Cell death occurred at the boundary between zR and the medulla, where many resident macrophages were present. These findings also suggested that $\mathrm{zU}$ apparently functions in the development and maintenance of the cortical zonation.

6-5) Possible function of $\mathrm{zU}$ cells as stem/ progenitor cells in the maintenance of the functional zonation of rat adrenal cortex. Despite important functions of adrenocortical zones, the origin of new parenchymal tissue and the mecha$\operatorname{nism}(\mathrm{s})$ for the formation of the adrenocortical zones have been controversial (reviewed in refs. 106 and 107). The most prevailing hypothesis is the "cell migration theory" "108)-111) based on mainly the behavior of incorporated BrdU, tritiated thymidine, or trypan blue. This hypothesis states that the cells in the three zones arise from a common stem cell in the capsule or in the subcapsular region, then migrate centripetally to the inner zones, with concomitant changes in their specific functions, and finally die at the boundary between $\mathrm{zR}$ and the medulla. Therefore, cells are born as zG cells at a single site of cell production and with centripetal migration transform into $\mathrm{zF}$ cells, and finally become $\mathrm{zR}$ cells. An alternative hypothesis is the "zonal theory"112) which suggests that each zone replenishes its own cells independently, and that the cells die locally. The latter hypothesis, however, is not consistent with the results of the enucleation experiments stated above, which showed that enucleated adrenals including only zG and $\mathrm{z} U$ cells were functionally regenerated to restore three cortical zones.

However, neither theory fits our findings. As stated, we identified a new zone, $\mathrm{zU}$, in the rat adrenal cortex that does not express any zone-specific steroidogenic markers, CYP11B2 and CYP11B1, and observed two distinct proliferation sites in and around $\mathrm{zU} .{ }^{90)}$ It should be noted here that the cells around the stem cell layer are in general more active with respect to cell proliferation than those in the stem cell layer. ${ }^{92)}$ The two replicating sites locate in close proximity to each other, but differ in their responses toward external stimuli as will be described more precisely below. This fact is of special importance in considering the mechanism(s) for the formation and maintenance of the zonal structure and zone-specific functions of the adrenal cortex.

In Na-deficient rats, where the RAS is activated resulting in increase in the expression of CYP11B2 in $\mathrm{zG}$, the number of the BrdU-positive cells was high in the innermost portion of $\mathrm{zG}$, i.e., in the outer portion of $\mathrm{zU}$. On the other hand, ACTH injection induced a large increase in BrdU-positive cells in the outer $\mathrm{zF}$ with the suppression of CYP11B2 expression in $\mathrm{zG}$ and the increment of CYP11B1 expression in zFR, while $\mathrm{zU}$ almost disappeared. Under stimulation of both ACTH and RAS, BrdU-positive nuclei were concentrated at the boundary between $\mathrm{zG}$ and $z F .{ }^{113), 114)}$ On the basis of these findings together with the previously mentioned results that cells in $\mathrm{zU}$ are undifferentiated in terms of steroidogenic activity, and migrate from the $\mathrm{zU}$ bidirectionally, we proposed that the $\mathrm{zU}$ contains the stem/progenitor cells for the adrenal cortex differentiating to $\mathrm{zG}$ or to $\mathrm{zFR}$ cells ${ }^{90)}$ (Fig. 12). In 2002, we established cell lines displaying the phenotype similar to that of $\mathrm{zU}$ from adrenal glands of adult transgenic mice harboring a temperature-sensitive SV40 T-antigen gene. One of the cell lines successfully differentiated to zFlike cells expressing CYP11B1 mRNA at the nonpermissive temperature for SV40 T-antigen in the presence of cAMP analogue. Unfortunately none of cell lines have differentiated to CYP11B2 mRNAexpressing zG-like cells. ${ }^{115)}$

\section{Epilogue}

Our success in the purification of the zonespecific steroid hydroxylases, CYP11B2 in zG and CYP11B1 in zFR, ${ }^{75)}$ and making those antibodies ${ }^{80)}$ led to the discovery of an undifferentiated cell zone $(\mathrm{zU})$ between $\mathrm{zG}$ and $\mathrm{zF}$ in the Sprague-Dawley rat adrenal gland immunohistochemically. ${ }^{81)}$ We proposed that cells in $\mathrm{zU}$ are the stem/progenitor cells based on several lines of evidence described above. ${ }^{90)}$ On the other hand, some groups have reported that mice or Wistar rats have stem/progenitor cells in the capsule or in the subcapsular region $(\mathrm{zG})$ of the adrenal gland (refer to refs. 66 and 106). Just recently species variation was recognized as the 


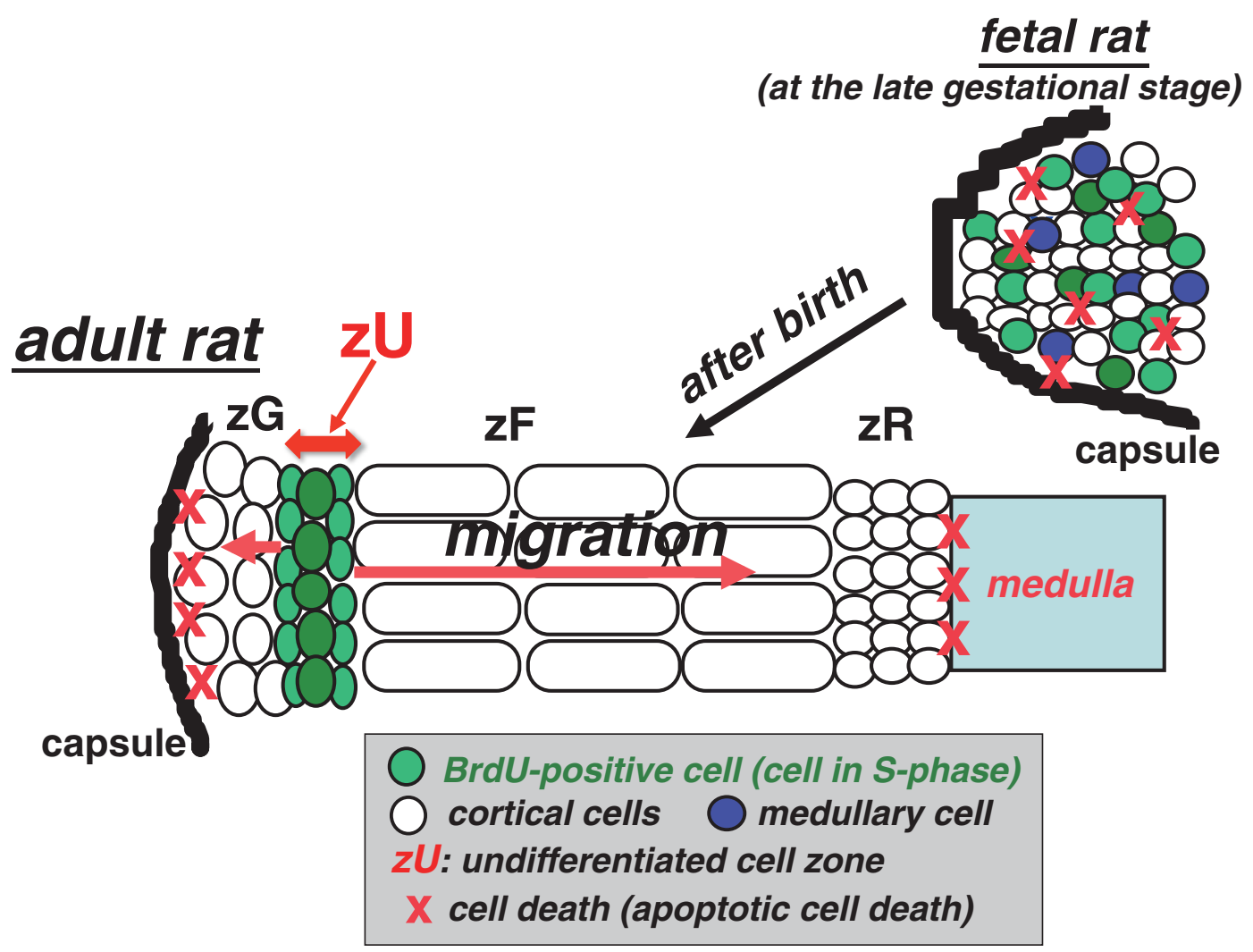

Fig. 12. Proposed mechanism on the development and maintenance of the functional zonation of the rat adrenal cortex. In fetal adrenal gland, medullary and cortical cells (mostly zF cells) are intermingled. BrdU-positive cells (cells in S-phase) are scattered over the gland and proliferate without apparent movement. After birth, the cortical zonation becomes distinct with zU. At the mature stage, BrdU-positive cells are concentrated in and around the $\mathrm{zU}$ and migrate bidirectionally. Cells differentiating to $\mathrm{zF}$ cells migrate centripetally and then transform into zR cells. They finally degenerate at the boundary between zR and the medulla. Meanwhile cells differentiating into zG cells migrate centrifugally and may degenerate within zG. zG: zona glomerulosa, zF: zona fasciculata, zR: zona reticularis, zU: undifferentiated cell zone.

mechanism for development and maintenance of the adrenal gland, and it is realized that data obtained using one species do not necessarily apply to other species. One example is described below.

The hedgehog pathway has been found to be involved in the development of a number of vertebral organ systems and the regulation of both embryonic and adult tissue stem cells. ${ }^{116), 117)}$ In 2009, King's group showed in the mouse adrenal cortex that the Sonic hedgehog (Shh) is expressed in relatively undifferentiated steroidogenic cells of $\mathrm{zG}$, and is required for the adrenal development. ${ }^{118)}$ However, in 2011, the same group reported using rat adrenal gland that Shh expressing cells are detected exclusively in the outer half region of zU. ${ }^{119)}$ More recently, in 2013, they also showed that Dlk1 ( $\delta$-like homologue 1 and also named Pref-1: preadipocyte factor- $1^{120)}$ ), an inhibitor of adipocyte differentiation, is coexpressed with Shh in zU of the rat adrenal gland. ${ }^{121)}$
Thus, the subcapsular arrangement of Shh positive cells clearly differed between mouse and rat adrenal glands. As stated earlier, in the mouse adrenal gland, a zone equivalent to $\mathrm{zU}$ is hardly observed between $\mathrm{zG}$ and $\mathrm{zF}$, because, in the mouse, the CYP11B2 positive cells are observed in clusters underneath the capsule. In fact, King's group observed in mouse adrenal gland that Shh-positive cells did not form a continuous layer but formed discrete clusters intermingled with clusters of CYP11B2-positive cells, ${ }^{118)}$ although in rat adrenal cortex, Shh-positive cells are present in a continuous layer immediately underneath the $\mathrm{zG}$, i.e., $\mathrm{zU}^{119)}$ Even in rats, strain differences exist, e.g. the thickness of $\mathrm{zU}$ in Wistar rats is very thin when compared with that in Sprague-Dawley rats. ${ }^{119)}$ These species and strain differences in the structure of the adrenal gland may lead to confusing data from various groups. Our recent study on human adrenocortical 
zonation showed the CYP11B2/CYP11B1-negative cells mostly among CYP11B2-positive cell clusters, ${ }^{122)}$ suggesting that the zonation of the human cortex is rather similar to that of mouse adrenal cortex. King's group also suggested that BrdUpositive cells are descendants of the Shh-positive cells of $\mathrm{zU}$ in the rat adrenal gland. Interestingly some Shh/CYP11B2-positive cells were observed in zG, suggesting that Shh-positive cells also migrated outwards from the Shh-containing layer (zU) and converted to zG cells. ${ }^{119)}$

Taken together, observations by King's group $^{119), 121)}$ are consistent with our hypothesis that cells in $\mathrm{zU}$ of the rat adrenal gland are the stem/ progenitor cells. Further studies, however, on the stem/progenitor cells are necessary, such as the isolation of stem/progenitor cells from the adrenal gland and examining the ability to differentiate to zone-specific cortical cells, in order to understand more precisely the development and maintenance of the functional zonation of the adrenal cortex.

\section{Acknowledgement}

I wish to express my gratitude especially to Professor Tamio Yamakawa for recommending me to write this review. I am grateful to Dr. Shigeo Horie, Professor Emeritus, Kitasato University School of Medicine and Dr. Tamio Yamakawa, Professor Emeritus, Faculty of Medicine, The University of Tokyo for stimulatory guidance and critical discussions. I am also grateful to Dr. Yuzuru Ishimura, Professor Emeritus, School of Medicine, Keio University, Dr. Arata Ichiyama, Professor Emeritus, Hamamatsu University School of Medicine, Dr. Osamu Hayaishi, Professor Emeritus, Faculty of Medicine Kyoto University, Dr. Keiichi Watanabe, the late Professor, Tokai University School of Medicine and Dr. Makoto Suematsu, Professor, School of Medicine, Keio University, for their constant encouragement and advice. I am greatly indebted to many collaborators for accomplishment of these works. Especially I wish to acknowledge Dr. Tadashi Ogishima, Faculty of Sciences Kyushu University, Dr. Kuniaki Mukai, Dr. Hirokuni Miyamoto and Dr. Hiroshi Suzuki, School of Medicine, Keio University, and Dr. Shinichi Izumi, Nagasaki University School of Dentistry. The excellent technical assistance of T. Ebina, M. Fuse, R. Hoshino, M. Kondo, C. Motomura, Y. Nagasawa, T. Ogawa, and N. Tanabe is also greatly acknowledged.

This study has been supported by Grant-in-aid for General Scientific Research from the Ministry of Education, Science and Culture, Japan, and by grants from the Mitsubishi Foundation, Takeda Science Foundation, Tanabe Science Foundation, Tsumura Foundation, Uehara Memorial Foundation, and Keio University.

\section{References}

1) Eustachi, B. (1563) Opuscula Anatomica, Vincentius Luchinus, Venice.

2) Addison, T. (1855) On the constitutional and local effect of disease of the supra-renal capsules. Samuel Highley, London.

3) Dale, H. (1949) Thomas Addison: Pioneer of endocrinology. British Med. J., Aug. 13, 347-352.

4) Orth, D.N., Kavacs, W.J. and Rowan, D.C. (1992) The adreal cortex. In Wilson's Textbook of Endocrinology (eds. Wilson, J.D. and Foster, D.W.). Sanders, Philadelphia, pp. 489-619.

5) Arnold, J. (1866) Ein Beitrag zür feineren Struktur und dem Chemismus der Nebennieren. Arch. Pathol. Anat. Physiol. Klin. Med. 35, 64-107.

6) Swingle, W.W. and Pfiffner, J.J. (1930) An aqueous extract of the suprarenal cortex which maintains the life of bilaterally adrenalectomized cats. Science 71, 321-322.

7) Swingle, W.W. and Pfiffner, J.J. (1930) Further observation on adrenalectomized cats treated with an aqueous extract of the suprarenal cortex. Science 71, 489-490

8) Harrop, G.A., Pfiffner, J.J., Weinstein, A. and Swingle, W.W. (1931) Further studies on the adrenal hormone. Science 73, 683-684.

9) Rowntree, L.G. and Greene, C.H. (1930) The treatment of patients with Addison's disease with the "cortical hormone" of Swingle and Pfiffner. Science 72, 482-483.

10) Ball, R.G. and Lansbury, J. (1931) The treatment of a case of Addison's disease with the cortical hormone of Swingle and Pfiffner. Can. Med. Assoc. J. 24, 695-697.

11) Wintersteiner, O. and Pfiffner, J.J. (1935) Chemical studies on the adrenal cortex. II. Isolation of several physiologically inactive crystalline compounds from active extracts. J. Biol. Chem. 111, 599-612.

12) Steiger, M. and Reichstein, T. (1937) Desoxycorticosteron (21-oxy-progesterone) aus $\Delta^{5}$-3-oxy-ätiocholensäure (XII. Mitteilung über Bestandteile der Nebennieren-Rinde). Helv. Chim. Acta 20, $1164-1179$.

13) Kendall, E.C. (1949) The chemistry and partial synthesis of adrenal steroids. Ann. N. Y. Acad. Sci. 50, 540-547.

14) Hench, P.S., Kendall, E.C., Slocumb, C.H. and Polley, H.F. (1949) The effect of a hormone of the adrenal cortex (17-hydroxy-11-dehydrocorticosterone: compound E) and of pituitary adrenocorticotropic hormone on rheumatoid arthritis. Preliminary report. Ann. Rheum. Dis. 8, 97-104.

15) Kendall, E.C. (1951) The adrenal cortex and 
rheumatoid arthritis. British Med. J., Dec. 1, $1295-1299$.

16) Simpson, S.A., Tait, J.F., Wettstein, A., Neher, R., von Euw, J., Schindler, O. and Reichstein, T. (1954) Konstitution des Aldosterons, des neuen Mineralocorticoids. Experientia 10, 132-133.

17) Tait, J.F., Simpson, S.A. and Grundy, H.M. (1952) The effect of adrenal extract on mineral metabolism. Lancet, Jan. 19, 122-124.

18) Speirs, R.S., Simpson, S.A. and Tait, J.F. (1954) Certain biological activities of crystalline electrocortin. Endocrinology 55, 233-236.

19) Simpson, S.A. and Tait, J.F. (1952) A quantitative method for the bioassay of the effect of adrenal cortical steroids on mineral metabolism. Endocrinology 50, 150-161.

20) Hayano, M. and Dorfman, R.I. (1952) The action of adrenal homogenates on progesterone, 17hydroxyprogesterone and 21-desoxycortisone. Arch. Biochem. Biophys. 36, 237-238.

21) Hayano, M., Lindberg, M.C., Dorfman, R.I., Hancock, J.E.H. and von Doering, W.E. (1955) On the mechanism of the $\mathrm{C}$-11 $\beta$-hydroxylation of steroids; A study with $\mathrm{H}_{2} \mathrm{O}^{18}$ and $\mathrm{O}_{2}{ }^{18}$. Arch. Biochem. Biophys. 59, 529-532.

22) Ryan, K.J. and Engel, L.L. (1957) Hydroxylation of steroids at carbon 21. J. Biol. Chem. 225, 103114 .

23) Cooper, D.Y., Estabrook, R.W. and Rosenthal, O. (1963) The stoichiometry of $\mathrm{C}_{21}$ hydroxylation of steroids by adrenocortical microsomes. J. Biol. Chem. 238, 1320-1323.

24) Mason, H.S., Fowlks, W.L. and Peterson, E. (1955) Oxygen transfer and electron transport by the phenolase complex. J. Am. Chem. Soc. 77, 29142915.

25) Hayaishi, O., Rothberg, S. and Mehler, A.H. (1956) Abstracts, American Chemical Society, 130th meeting, Atlantic City, 53C.

26) Klingenberg, M. (1957) Pigments of rat liver microsomes. Arch. Biochem. Biophys. 75, 376386.

27) Omura, T. and Sato, R. (1962) A new cytochrome in liver microsomes. J. Biol. Chem. 237, PC1375PC1376.

28) Omura, T. and Sato, R. (1964) The carbon monoxide-binding pigment of liver microsomes. I. Evidence for its hemoprotein nature. J. Biol. Chem. 239, 2370-2378.

29) Estabrook, R.W., Cooper, D.Y. and Rosenthal, O. (1963) The light-reversible carbon monoxide inhibition of the steroid C-21 hydroxylation system of the adrenal cortex. Biochem. Z. 338, $741-755$.

30) Cooper, D.Y., Levis, L., Narasimhulu, S., Rosenthal, O. and Estabrook, R.W. (1965) Photochemical action spectrum of the terminal oxidase of mixed function oxidase systems. Science 147, 400-402.

31) Estabrook, R.W. (2003) A passion for P450s (Remembrances of the early history of research on cytochrome P450). Drug Metab. Dispos. 31, 1461-1473.
32) Halkerston, I.D.K., Eichhorn, J. and Hecter, O. (1961) A requirement for reduced triphosphopyridine nucleotide for cholesterol side-chain cleavage by mitochondrial fractions of bovine adrenal cortex. J. Biol. Chem. 236, 374-380.

33) Shimizu, K., Gut, M. and Dorfman, R.I. (1962) $20 \alpha$, $22 \varepsilon$-dihydroxycholesterol, an intermediate in the biosynthesis of pregnenolone ( $3 \beta$-hydroxypregn- 5 en-20-on) from cholesterol. J. Biol. Chem. 237, 699-702.

34) Simpson, E.R. and Boyd, G.S. (1966) The cholesterol side-chain cleavage system of the adrenal cortex: A mixed-function oxidase. Biochem. Biophys. Res. Commun. 24, 10-17.

35) Greengard, P., Psychoyos, S., Tallan, H.H., Cooper, D.Y., Rosenthal, O. and Estabrook, R.W. (1967) Aldosterone synthesis by adrenal mitochondria. III. Participation of cytochrome P-450. Arch. Biochem. Biophys. 121, 298-303.

36) Omura, T. (2011) Recollection of the early years of the research on cytochrome P450. Proc. Jpn. Acad. Ser. B 87, 617-640.

37) Takemori, S. and Kominami, S. (1984) The role of cytochrome $\mathrm{P} 450$ in adrenal steroidogenesis. Trends Biochem. Sci. 9, 393-396.

38) Jefcoate, C.R., Hume, R. and Boyd, G.S. (1970) Separation of two forms cytochrome P450: Adrenal cortex mitochondria. FEBS Lett. 9, 41-44.

39) Isaka, S. and Hall, P.F. (1971) Soluble cytochrome P450 from bovine adrenocortical mitochondria. Biochem. Biophys. Res. Commun. 43, 747-753.

40) Narasimhulu, S., Cooper, D.Y. and Rosenthal, O. (1965) Spectrophotometric properties of a Tritonclarified steroid 21-hydroxylase system of adrenocortical microsomes. Life Sci. 4, 2101-2107.

41) Omura, T. and Sato, R. (1964) The carbon monoxide-binding pigment of liver microsomes II. Solubilization, purification, and properties. J. Biol. Chem. 239, 2379-2385.

42) Kinoshita, T. (1967) Studies on P450: IV. Properties of a solubilized and partially purified preparation of P450 from adrenal cortex mitochondria. Tokyo J. Med. Sci. 75, 202 (abstr., in Japanese).

43) Mitani, F. and Horie, S. (1969) Studies on P-450: V. On the substrate-induced spectral change of P-450 solubilized from bovine adrenocortical mitochondria. J. Biochem. 65, 269-280.

44) Kimura, T., Nakamura, S., Huang, J.J., Chu, J., Wang, H. and Tsernoglou, D. (1973) Electron transport system for adrenocortical mitochondrial steroid hydroxylation reactions: The mechanism of the hydroxylation reactions and properties of the flavoprotein-iron-sulfur protein complex. Ann. N. Y. Acad. Sci. 212, 94-106.

45) Takemori, S., Suhara, K., Hashimoto, S. and Hashimoto, M. (1975) Purification of cytochrome P-450 from bovine adrenocortical mitochondria by an "Aniline-Sepharose" and the properties. Biochem. Biophys. Res. Commun. 63, 588-593.

46) Takemori, S., Sato, H., Gomi, T., Suhara, K. and Katagiri, M. (1975) Purification and properties of cytochrome $\mathrm{P}_{450_{11 \beta}}$ from adrenocortical mito- 
chondria. Biochem. Biophys. Res. Commun. 67, $1151-1157$.

47) Mitani, F. and Horie, S. (1969) Studies on P-450: VI. Spin state of P-450 solubilized from bovine adrenocortical mitochondria. J. Biochem. 66, 139-149.

48) Mitani, F. and Horie, S. (1970) Studies on P-450: VII. Reconstitution of a steroid $11 \beta$-hydroxylation system using a $\mathrm{P} 450$ preparation extracted and partially purified from adrenocortical mitochondria. J. Biochem. 68, 529-542.

49) Mitani, F., Ichiyama, A., Masuda, A. and Ogata, I. (1975) Enzymatic studies on adrenocortical deoxycorticosterone $11 \beta$-hydroxylase system. J. Biol. Chem. 250, 8010-8015.

50) Mitani, F., Ando, N. and Horie, S. (1973) Preparation and properties of mitochondrial cytochrome P450 from bovine adrenal cortex. Ann. N. Y. Acad. Sci. 212, 208-226.

51) Horie, S. and Morrison, M. (1965) In Oxidases and related redox system. Vol. 2 (eds. King, T.E., Mason, H.S. and Morrison, M.) John Wiley and Sons, New York.

52) Schenkman, J.B., Remmer, H. and Estabrook, R.W. (1967) Spectral studies of drug interaction with hepatic microsomal cytochrome. Mol. Pharmacol. 3, 113-123.

53) Williams-Smith, D.L. and Cammack, R. (1977) Oxidation-reduction potentials of cytochromes P-450 and ferredoxin in the bovine adrenal. Their modification by substrates and inhibitors. Biochim. Biophys. Acta 499, 432-442.

54) Huang, J.J. and Kimura, T. (1971) A specific role of reduced adrenodoxin in adrenal mitochondrial steroid hydroxylases. Biochem. Biophys. Res. Commun. 44, 1065-1070.

55) Kimura, T. and Suzuki, K. (1965) Enzymatic reduction of non-heme iron protein (adrenodoxin) by reduced nicotinamide adenine dinucleotide phosphate. Biochem. Biophys. Res. Commun. 20, 373-379.

56) Omura, T., Sanders, E. and Estabrook, R.W. (1966) Isolation from adrenal cortex of a nonheme iron protein and a flavoprotein functional as a reduced triphosphopyridine nucleotide-cytochrome P450 reductase. Arch. Biochem. Biophys. 117, 660 673.

57) Simpson, E.R. and Boyd, G.S. (1967) Partial resolution of the mixed-function oxidase involved in the cholesterol side-chain cleavage reaction in bovine adrenal mitochondria. Biochem. Biophys. Res. Commun. 28, 945-950.

58) Suhara, K., Ikeda, Y., Takemori, S. and Katagiri, M. (1972) The purification and properties of NADPH-adrenodoxin reductase from bovine adrenocortical mitochondria. FEBS Lett. 28, 45-47.

59) Suhara, K., Takemori, S. and Katagiri, M. (1972) Improved purification of bovine adrenal ironsulfur protein. Biochim. Biophys. Acta 263, $272-278$.

60) Katagiri, M., Takikawa, O., Sato, H. and Suhara, K. (1977) Formation of a cytochrome P450scc- adrenodoxin complex. Biochem. Biophys. Res. Commun. 77, 804-809.

61) Kido, T. and Kimura, T. (1979) The formation of binary and ternary complexes of cytochrome $\mathrm{P} 450$ scc with adrenodoxin and adrenodoxin reductase-adrenodoxin complex. The implication in ACTH function. J. Biol. Chem. 254, 1180611815

62) Beilke, D., Weiss, R., Löhr, F., Pristvšek, P., Hannemann, F., Bernhardt, R. and Rüterjans, H. (2002) A new electron transport mechanism in mitochondrial steroid hydroxylase systems based on structural changes upon the reduction of adrenodoxin. Biochemistry 41, 7969-7978.

63) Giroud, C.J.P., Stachenko, J. and Venning, E.H. (1956) Secretion of aldosterone by the zona glomerulosa of rat adrenal glands incubated in vitro. Proc. Soc. Exp. Biol. Med. 92, 154-158.

64) Giroud, C.J.P. and Stachenko, J. (1964) Further observations on the functional zonation of the adrenal cortex. Can. J. Biochem. 42, 1777-1786.

65) Nebert, D.W., Adesnik, M., Coon, M.J., Estabrook, R.W., Gonzalez, F.J., Guengerich, F.P., Gunsalus, I.C., Johnson, E.F., Kemper, B., Levin, W., Phillips, I.R., Sato, R. and Waterman, M.R. (1987) The P450 gene superfamily: recommended nomenclature. DNA 6, $1-11$.

66) Vinson, G.P. (2003) Adrenocortical zonation and ACTH. Microsc. Res. Tech. 61, 227-239.

67) Papadopoulos, V. and Miller, W.L. (2012) Role of mitochondrial steroidogenesis. Best Pract. Res. Clin. Endocrinol. Metab. 26, 771-790.

68) Kominami, S., Ochi, H., Kobayashi, Y. and Takemori, S. (1980) Studies on the steroid hydroxylation system in adrenal cortex microsomes. Purification and characterization of cytochrome P-450 specific for steroid C-21 hydroxylation. J. Biol. Chem. 255, 3386-3394.

69) Kominami, S., Shinzawa, K. and Takemori, S. (1982) Purification and some properties of cytochrome P-450 specific for steroid $17 \alpha$-hydroxylation and $\mathrm{C} 17-\mathrm{C} 20$ bond cleavage from guinea pig adrenal microsomes. Biochem. Biophys. Res. Commun. 109, 916-921.

70) Sato, H., Ashida, N., Suhara, K., Itagaki, E. Takemori, S. and Katagiri, M. (1978) Properties of an adrenal cytochrome P450 (P450 113 ) for the hydroxylations of corticosteroids. Arch. Biochem. Biophys. 190, 307-314.

71) Ogishima, T., Mitani, F. and Ishimura, Y. (1989) Isolation of two distinct cytochromes P450 113 with aldosterone synthase activity from bovine adrenocortical mitochondria. J. Biol. Chem. 105. 497-499.

72) Ikushiro, S., Kominami, S. and Takemori, S. (1992) Adrenal P450scc modulates activity of P450 $11 \beta$ in liposomal and mitochondrial membranes. Implication of P450scc in zone specificity of aldosterone biosynthesis in bovine adrenal. J. Biol. Chem. 267, 1464-1469.

73) Lauber, M., Sugano, S., Ohnishi, T., Okamoto, M. 
and Müller, J. (1987) Aldosterone biosynthesis and cytochrome P450 $11 \beta$ : Evidence for two different forms of the enzyme in rats. J. Steroid Biochem. 26, 693-698.

74) Deane, H.W., Shaw, J.H. and Greep, R.O. (1948) The effect of altered sodium or potassium intake on the zona glomerulosa of the rat's adrenal cortex. Endocrinology 43, 133-153.

75) Ogishima, T., Mitani, F. and Ishimura, Y. (1989) Isolation of aldosterone synthase cytochrome P450 from zona glomerulosa mitochondria of rat adrenal cortex. J. Biol. Chem. 264, 10935-10938.

76) Ogishima, T., Shibata, H., Shimada, H., Mitani, F., Suzuki, H., Saruta, T. and Ishimura, Y. (1991) Aldosterone synthase cytochrome P450 expressed in the adrenals of patients with primary aldosteronism. J. Biol. Chem. 266, 10731-10734.

77) Mitani, F., Shimizu, T., Ueno, R., Ishimura, Y., Izumi, S., Komatsu, N. and Watanabe, K. (1982) Cytochrome $\mathrm{P} 450_{11 \beta}$ and $\mathrm{P} 450 \mathrm{scc}$ in adrenal cortex: Zonal distribution and intramitochondrial localization by the horseradish peroxidase-labeled antibody method. J. Histochem. Cytochem. 30, 1066-1074.

78) Mitani, F., Ishimura, Y., Izumi, S. and Watanabe, K. (1979) Immunohistochemical localization of adrenodoxin and adrenodoxin reductase in bovine adrenal cortex. Acta Endocrinol. (Copenh.) 90, $317-327$.

79) Ishimura, K. and Fujita, H. (1997) Light and electron microscopic immunohistochemistry of the localization of adrenal steroidogenic enzymes. Microsc. Res. Tech. 36, 445-453.

80) Ogishima, T., Suzuki, H., Hata, J., Mitani, F. and Ishimura, Y. (1992) Zone-specific expression of aldosterone synthase cytochrome P450 and cytochrome $\mathrm{P} 450_{11 \beta}$ in rat adrenal cortex: Histochemical basis for the functional zonation. Endocrinology 130, 2971-2977.

81) Mitani, F., Suzuki, H., Hata, J., Ogishima, T., Shimada, H. and Ishimura, Y. (1994) A novel cell layer without corticosteroid-synthesizing enzymes in rat adrenal cortex: Histochemical detection and possible physiological role. Endocrinology 135, 431-438.

82) Shinzawa, K., Ishibashi, S., Murakoshi, M., Watanabe, K., Kominami, S., Kagawa, A. and Takemori, S. (1988) Relationship between zonal distribution of microsomal cytochrome P450s $\left(\mathrm{P} 450_{17 \alpha, \text { lyase }}\right.$ and $\left.\mathrm{P} 450_{\mathrm{C} 21}\right)$ and steroidogenic activities in guinea pig adrenal cortex. J. Endocrinol. 119, 191-200.

83) Sasano, M., Mason, J.I. and Sasano, N. (1988) Immunohistochemical study of cytochrome $\mathrm{P} 450_{17 \alpha}$ in human adrenocortical disorders. Hum. Pathol. 20, 113-117.

84) Takayama, K., Morohashi, K., Honda, S., Hara, N. and Omura, T. (1994) Contribution of Ad4BP, a steroidogenic cell-specific transcription factor, to regulation of the human CYP11A and bovine CYP11B genes through their distal promoters. J. Biochem. 116, 193-203.
85) Tobin, C.E. and Whitehead, R. (1942) Age and sex variations in the fat of the adrenal cortex of the white rat. J. Anat. 76, 342-346.

86) Carter, D.B. and Lever, J.D. (1954) The zone intermedia of the adrenal cortex. A correlation of possible functional significance with development morphology and histochemistry. J. Anat. 88, 437-454.

87) Greep, R.O. and Deane, H.W. (1947) Cytochemical evidence for the cessation of hormone production in the zona glomerulosa of the rat's adrenal cortex after prolonged treatment with deoxycorticosterone acetate. Endocrinology 40, 417-425.

88) Miyamoto, H., Mitani, F., Mukai, K. and Ishimura, Y. (1999) Studies on cytogenesis in adult rat adrenal cortex: Circadian and zonal variations and their modulation by adrenocorticotropic hormone. J. Biochem. 128, 1175-1183.

89) Miyamoto, H., Mitani, F., Mukai, K., Suematsu, M. and Ishimura, Y. (2000) A low-sodium diet affects the proliferation and migration of rat adrenocortical cells in vivo. In Molecular Steroidogenesis (eds. Okamoto, M., Ishimura, Y. and Nawata, H.). Universal Academy Press, Tokyo, pp. 225-228.

90) Mitani, F., Mukai, K., Miyamoto, H., Suematsu, M. and Ishimura, Y. (2003) The undifferentiated cell zone is a stem cell zone in adult rat adrenal cortex. Biochim. Biophys. Acta 1619, 317-324.

91) Miyamoto, H., Mitani, F., Mukai, K., Suematsu, M. and Ishimura, Y. (2000) Daily regeneration of rat adrenocortical cells: Circadian and zonal variations in cytogenesis. Endocr. Res. 26, 899-904.

92) Potten, C.S. and Loeffler, M. (1990) Stem cells: attributes, cycles, spirals, pitfalls and uncertainties. Lessons for and from the crypt. Development 110, 1001-1020.

93) Holmberg, J., Genander, M., Helford, M.M., Annerén, C., Sondell, M., Chumley, M.J., Silvany, R.E., Henkemeyer, M. and Frisén, J. (2006) EphB receptors coordinate migration and proliferation in the intestinal stem cell niche. Cell 125, 1151-1163.

94) Jaffe, H. and Plavska, A. (1926) Functioning autoplastic suprarenal transplants. Proc. Soc. Exp. Biol. Med. 23, 528-530.

95) Ingle, D.J. and Higgins, G.M. (1938) Autotransplantation and regeneration of the adrenal gland. Endocrinology 22, 458-464.

96) Belloni, A.S., Neri, G., Musajo, F.G., Andreis, P.G., Boscaro, M., D'Agostino, D., Rebuffat, P., Boshier, D.P., Gottardo, G., Mazzocchi, G. and Nussdorfer, G.G. (1990) Investigation on the morphology and function of adrenocortical tissue regenerated from gland capsular fragments autotransplanted in the musculus gracilis of the rat. Endocrinology 126, 3251-3262.

97) Thomas, M., Northrup, S.R. and Hornsby, P.J. (1997) Adrenocortical tissue formed by transplantation of normal clones of bovine adrenocortical cells in scid mice replaces the essential functions of the animals' adrenal glands. Nat. Med. 3, 978-983. 
98) Greep, R.O. and Dean, H.W. (1949) Histological, cytochemical and physiological observation on the regeneration of the rat's adrenal gland following enucleation. Endocrinology 45, 42-56.

99) Skelton, F. (1959) Adrenal regeneration and adrenal-regeneration hypertension. Physiol. Rev. 39, $162-182$.

100) Mitani, F., Ogishima, T., Miyamoto, H. and Ishimura, Y. (1995) Localization of P450aldo and $\mathrm{P} 450_{11 \beta}$ in normal and regenerating rat adrenal cortex. Endocr. Res. 21, 413-423.

101) Mitani, F. and Ishimura, Y. (2002) Steroid monooxygenases as markers for studying functional zonation in the adrenal cortex. Int. Congr. Ser. 1233, 99-114.

102) Ingle, D.J. and Higgins, G.M. (1938) Regeneration of the adrenal gland following enucleation. Am. J. Med. Sci. 196, 232-239.

103) Ennen, W.B., Levay-Young, B.K. and Engeland, W.C. (2005) Zone-specific cell proliferation during adrenocortical regeneration after enucleation in rats. Am. J. Physiol. Endocrinol. Metab. 289, E883-E891.

104) Mitani, F., Mukai, K., Ogawa, T., Miyamoto, H. and Ishimura, Y. (1997) Expression of cytochromes P450aldo and $\mathrm{P}_{450_{11 \beta}}$ in rat adrenal gland during late gestational and neonatal stages. Steroids 62, 57-61.

105) Mitani, F., Mukai, K., Miyamoto, H., Suematsu, M. and Ishimura, Y. (1999) Development of functional zonation in the rat adrenal cortex. Endocrinology 140, 3342-3353.

106) Kim, A.C. and Hammer, G.D. (2007) Adrenocortical cells with stem/progenitor cell properties: Recent advances. Mol. Cell. Endocrinol. 265-266, $10-16$.

107) Wood, M.A. and Hammer, G.D. (2011) Adrenocortical stem and progenitor cells: Unifying mode of two proposed origins. Mol. Cell. Endocrinol. 336, 206-212

108) Göttschau, M. (1883) Struktur und embryonale Entwickelung der Nebennieren bei Säugetieren. Archiv. für Entwickelungsgeschichte. Anatomischer Abteilung 9, 412-458.

109) Zwemer, R.L., Wotton, R.M. and Norkus, M.G. (1938) A study of corticoadrenal cells. Anat. Rec. 72, 249-263.

110) Zajicek, G., Ariel, I. and Arber, N. (1986) The streaming adrenal cortex: direct evidence of centripetal migration of adrenocytes by estimation of cell turnover rate. J. Endocrinol. 111, 477482 .

111) Wright, N.A., Voncina, D. and Morley, A.R. (1973) An attempt to demonstrate cell migration from the zona glomerulosa in the prepubertal male rat adrenal cortex. J. Endocrinol. 59, 451-459.

112) Chester-Jones, J. (1948) Variation in the mouse adrenal cortex with special reference to the zona reticularis and to brown degeneration together with a discussion of the "cell migration" theory. Q. J. Microsc. Sci. 89, 53-73.

113) Miyamoto, H., Mitani, F., Mukai, K. and Ishimura, Y. (1998) Effects of ACTH and angiotensin II on the novel cell layer without corticosteroid-synthesizing activity in rat adrenal cortex. In Oxygen Homeostasis and its Dynamics (eds. Ishimura, Y., Shimada, H. and Suematsu, M.). Springer-Verlag, Tokyo, pp. 237-243.

114) Mitani, F., Miyamoto, H., Mukai, K. and Ishimura, Y. (1996) Effects of long term stimulation of ACTH- and angiotensin II-secretions on the rat adrenal cortex. Endocr. Res. 22, 421-431.

115) Mukai, K., Nagasawa, R., Agake-Suzuki, R., Mitani, F., Totani, K., Yanai, M., Obinata, M., Suematsu, M. and Ishimura, Y. (2002) Conditionally immortalized adrenocortical cell lines at undifferentiated states exhibit inducible expression of glucocorticoid-synthesizing genes. Eur. J. Biochem. 269, 69-81.

116) Ching, S. and Vilain, E. (2009) Targeted disruption of Sonic hedgehog in the mouse adrenal leads to adrenocortical hypoplasia. Genesis 47, 628-637.

117) Huang, C.C., Miyagawa, S., Matsumaru, D., Parker, K.L. and Yao, H.H. (2010) Progenitor cell expansion and organ size of mouse adrenal is regulated by Sonic hedgehog. Endocrinology 151, $1119-1128$

118) King, P., Paul, A. and Laufer, E. (2009) Shh signaling regulates adrenocortical development and identifies progenitors of steroidogenic lineages. Proc. Natl. Acad. Sci. U.S.A. 106, 2118521190.

119) Guasti, L., Paul, A., Laufer, E. and King, P. (2011) Localization of Sonic hedgehog secreting and receiving cells in the developing and adult rat adrenal cortex. Mol. Cell. Endocrinol. 336, 117122.

120) Sul, H.S. (2009) Pref-1: role in adipogenesis and mesenchymal cell fate. Mol. Endocrinol. 23, 17171725 .

121) Guasti, L., Cavlan, D., Cogger, K., Banu, Z., Shakur, A. and King, P. (2013) Dlk1 upregulates Gli1 expression in male rat adrenal capsule cells through the activation of $\beta 1$ integrin and ERK1-2. Endocrinology 154, 4675-4684.

122) Nishimoto, K., Nakagawa, K., Li, D., Kosaka, T., Oya, M., Mikami, S., Shibata, H., Itoh, H., Mitani, F., Yamazaki, T., Ogishima, T. Suematsu, M. and Mukai, K. (2010) Adrenocortical zonation in humans under normal and pathological conditions. J. Clin. Endocrinol. Metab. 95, 2296-2305.

(Received Dec. 10, 2013; accepted Mar. 7, 2014) 


\section{Profile}

Fumiko Mitani was born in Peking in 1942. She received her Bachelor's degree (1965) and Master's degree (1967) from Ochanomizu University. In 1967, she entered Graduate School of Medicine, The University of Tokyo, and started her research career with studies on steroid hormone biosynthesis in the adrenal cortex, especially on steroid synthesizing enzyme cytochrome P450, under the supervision of Prof. Shigeo Horie and Prof. Tamio Yamakawa. During the doctoral studies, she spent a year (1969-1970) at The Rockefeller University (Dr. A. Kappas's Laboratory) and another 1 year (19701971) at Harvard School of Public Health (Dr. H. A. Salhanick's Laboratory) as Research Associate, working mainly on the induction of P450.

After she obtained Ph.D. in medicine from The University of Tokyo in 1973, she

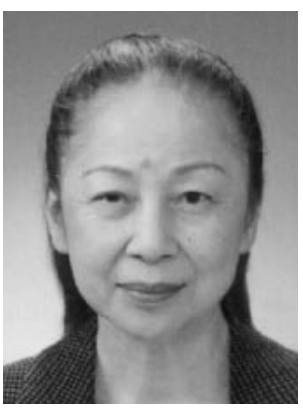
continued her research on kinetic studies of adrenocortical steroidogenesis with the advice of Prof. Arata Ichiyama and Prof. Osamu Hayaishi in Department of Physiological Chemistry and Nutrition, Faculty of Medicine, The University of Tokyo (1973-1974). After working as Research Associate at Hamamatsu University School of Medicine (1974-1975), she was employed as Research Associate in the laboratory of Prof. Yuzuru Ishimura, Department of Biochemistry, School of Medicine, Keio University (1975-1991) and then promoted to Senior Lecturer (1991-2008) of the same institution, where she performed with her collaborators pioneering work on the functional zonation of the adrenal cortex, showing the immunohistochemical localization of zone-specific enzymes. As the result, she found an undifferenciated cell zone of the rat adrenal cortex, which seems to be a stem/progenitor cell zone and maintain the functional zonation of the adrenal cortex. A part of the results is described in the Review Article.

In the period mentioned above, she worked with her interest in cytochrome P450 as Research Associate at Dr. H. A. Hill's laboratory of University of Oxford (1980.1-1980.3) and at Prof. B. R. Rabin's laboratory of University College of London (1980.4-1980.9).

After official retirement from Keio University, she worked as Senior Lecturer at the Faculty of Science and Engineering, Waseda University (2008-2013). 